\title{
THE FINANCIAL IMPACT OF CANCER IN CANADIAN YOUNG ADULTS
}

\author{
by (C) Kaitlyn Mahon A Thesis submitted
}

to the School of Graduate Studies in partial fulfillment of the

requirements for the degree of

Master of Science, Faculty of Science, Department of Psychology

Memorial University of Newfoundland

October 2020

St. John's Newfoundland and Labrador 
FINANCIAL IMPACT OF CANCER IN YOUNG ADULTS

\begin{abstract}
Cancer may have greater financial consequences for young adults (YAs), defined as those between 15 to 39, than older adults because of developmental stage. YA cancer survivors $(N=$ 575) reported on out-of-pocket cancer costs and missed work. They were compared to age, sex, and education-matched peers without cancer on income, debts and assets using data from the 2014 Canadian Financial Capability Survey and Canadian Community Health Survey. Almost $60 \%$ of YA survivors spent at least $\$ 100$ per month on out-of-pocket cancer-related expenses, and $49 \%$ missed at least one year of work. Groups did not differ in personal or household income. Compared to non-cancer peers in both groups, YA survivors were more likely to have outstanding credit card and line of credit balances. Regardless of current age or time since diagnosis, YA survivors were also more likely to not own assets while their non-cancer peers were more likely to be home owners. YAs face long-term financial impact due to cancer in assets and debts, but not in income.

Key words: cancer, young adults, financial toxicity, costs, health expenditures
\end{abstract}


FINANCIAL IMPACT OF CANCER IN YOUNG ADULTS

\section{General Summary}

Young Adults (YAs), defined as those between ages 15 and 39, with cancer face different challenges than children and older adults. One under recognized impact of a cancer diagnosis is the financial impact of cancer. The present study sought to determine the amount spent on cancer-related out-of-pocket expenses and amount of work missed. The study also compared how income, assets, and debts differ among Canadian YA cancer survivors and non-cancer peers. Almost $60 \%$ of YA survivors spent at least $\$ 100$ per month on out-of-pocket cancerrelated expenses, and $49 \%$ missed at least one year of work. YA survivors are more likely to have credit card and line of credit debt, and are less likely to own assets, such as homes or vehicles. Identifying financial hardships can improve quality of care through the creation of programs aimed at helping YAs and their families deal with financial hurdles. 
FINANCIAL IMPACT OF CANCER IN YOUNG ADULTS

\section{Acknowledgements}

I would first and foremost like to extend my sincerest gratitude to my supervisor, Dr.

Sheila Garland. Thank you for challenging, encouraging, and guiding me over the last couple of years. I am extremely grateful for your support and mentorship.

I would also like to thank my committee members, Drs. Ken Fowler and Lynn Gambin, for their guidance on this project.

I also thank Geoff Eaton and Karine Chalifour of Young Adult Cancer Canada, as well as lab member Breanna Lane for their dedication and contributions to this project. This project would not have been possible without them.

Finally, I would like to thank my family for their endless support and belief in me. This accomplishment would not have been possible without them. 
FINANCIAL IMPACT OF CANCER IN YOUNG ADULTS

\section{Table of Contents}

Abstract .ii

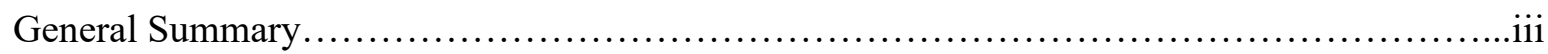

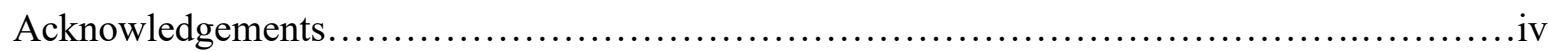

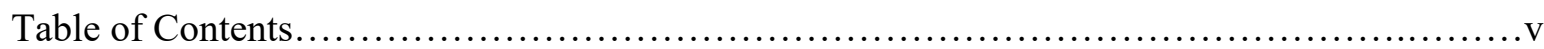

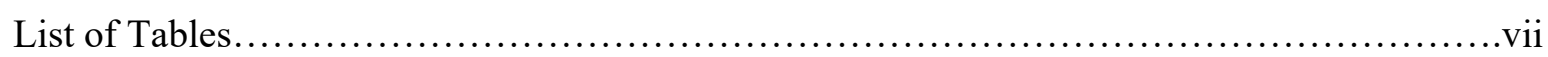

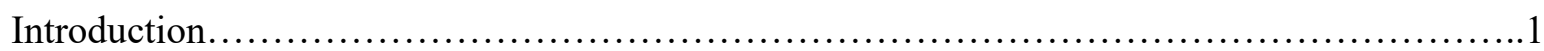

Financial Impact of Cancer on Individuals ..........................................

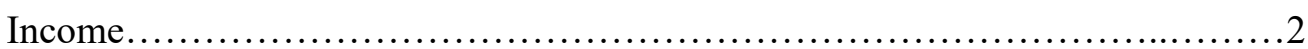

Out-of-pocket Health Care Costs.............................................

Unemployment and Absenteeism............................................

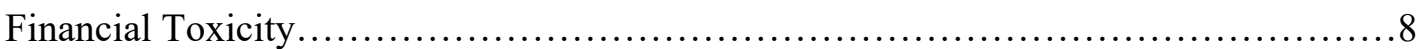

Cancer in Young Adults........................................................... 10

Factors that Contribute to the Financial Impact of Cancer in Young Adults.....11

Educational and Employment Disruption.............................11

Unemployment or Underemployment.............................13

Impact of Age on Financial Toxicity within the Young Adult Group..............15

Financial Impact of Cancer in Canadian Young Adults.............................. 16

Objectives of Current Study ................................................... 18

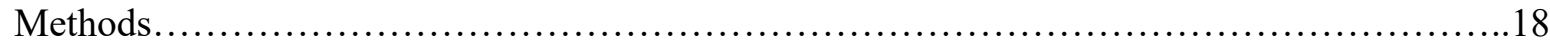

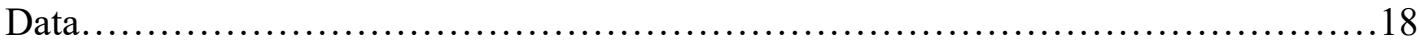

Measures.................................................................... 19

Statistical Analysis........................................................20

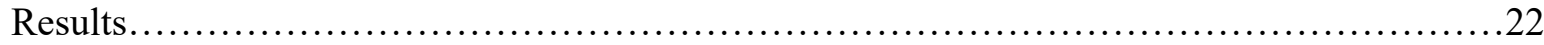


YACPRIME Sample Demographics..........................................22

Out-of-pocket Costs, Educational, and Occupational Impact.........................23

Financial Impact based on Current Age.........................................23

Income.............................................................. 24

Value and Type of Debts Carried......................................24

Value and Type of Assets Owned........................................24

Financial Recovery based on Time Since Diagnosis..............................25

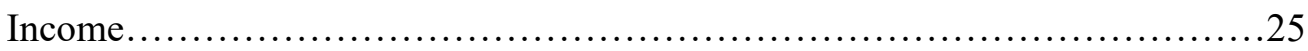

Value and Type of Debts Carried........................................25

Value and Type of Assets Owned.........................................26

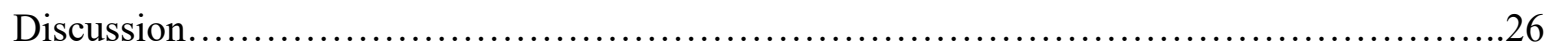

Challenges Specific to Young Adult Cancer Survivors................................27

Areas where Young Adult Cancer Survivors are Comparable to Non-cancer Peers......28

Areas where Young Adult Cancer Survivors are Not Comparable to Non-cancer Peers..28

Psychological Considerations................................................. 30

Limitations and Future Research............................................. 31

Recommendations for Policy Change and Support Interventions......................32

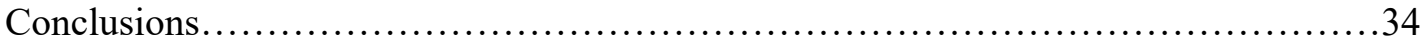

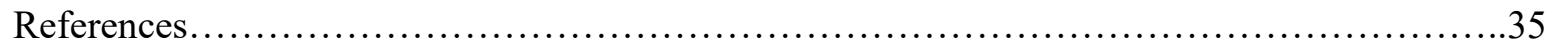

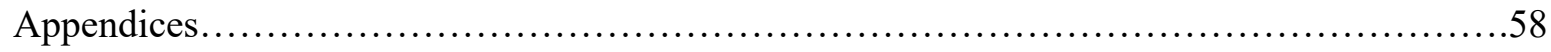

Appendix A: Financial Questions...........................................58

Appendix B: Ethics Approval.................................................60 
FINANCIAL IMPACT OF CANCER IN YOUNG ADULTS

\section{List of Tables}

Table 1: Summary of Comparisons.............................................. 50

Table 2. Summary Statistics for YACPRIME, CCHS and CFCS Comparison Samples..........51

Table 3: YACPRIME Sample $(N=575)$ Employment and Demographic Variables..............52

Table 4: Financial Impact of Cancer on YAs compared to Age, Sex and Education Matched

Controls Based on Current Age..................................................5 54

Table 5: Financial Impact of Cancer on YAs compared to Age, Sex and Education Matched

Controls Based on Time Since Diagnosis...........................................56 
FINANCIAL IMPACT OF CANCER IN YOUNG ADULTS

\section{Introduction}

The financial impact of a cancer diagnosis is underappreciated and has implications for society and individuals. Identifying and differentiating the financial burden of cancer for both individuals and society can provide a better estimate of the actual financial burden of cancer and can promote change in areas where survivors are financially disadvantaged due to cancer or its treatment. This information can also lend support for the need for changes that utilize a multipronged approach.

At the societal level, the economic burden of cancer care is substantial, in both Canada and the United States (US) (de Oliveira et al., 2018; Guy et al., 2013). In Canada, this economic burden mainly consists of public spending on hospital care, physician care and public and private spending on drug expenditures (de Oliveira et al., 2018) while in the US, the economic burden is largely comprised of private spending on ambulatory care, followed by inpatient care and prescription medications (Guy et al., 2013). The chronicity and complexity of cancer creates a heavy societal burden regardless of the type of healthcare system in place. In the US, the annual economic burden of cancer exceeded $\$ 16,000$ per survivor among adult cancer survivors diagnosed within one year (Guy et al., 2013). Additionally, net annual medical expenditures among cancer survivors in the US are estimated to be between $\$ 25.2$ to $\$ 41.7$ billion for 18 to 64 year old survivors and $\$ 37.3$ to $\$ 48.1$ billion for survivors 65 years and older (Guy et al., 2013). The rising economic burden of cancer care in Canada, which was $\$ 7.5$ billion in 2012, is more than double the $\$ 2.9$ billion cost in 2005 (de Oliveira et al., 2018). In terms of indirect costs, cancer cost the Canadian economy \$790.2 million in 2010 alone (Diener et al., 2018). The fastpaced increase in the direct and indirect costs of cancer is alarming and demonstrates the growing concern of resource and cost issues in healthcare (Canadian Institute for Health 


\section{FINANCIAL IMPACT OF CANCER IN YOUNG ADULTS}

Information, 2014). Moreover, cancer care spending in Canada accounted for over 3\% of annual healthcare spending in 2012 (Canadian Institute for Health Information, 2014), indicating the substantial cost of the illness. The high societal burden of cancer highlights the need to understand how cancer survivors themselves are financially impacted by cancer.

\section{Financial Impact of Cancer on Individuals}

At the individual level, the burden of cancer can be difficult to assess and can vary depending on the financial indices used. Income, out-of-pocket (OOP) expenses, employment status and absenteeism have been used in previous research to demonstrate how a cancer diagnosis can impact the financial well-being of individuals. Taken together, these studies indicate the negative financial toll a cancer diagnosis has on individuals and are discussed below.

\section{Income}

In many countries, the financial strain of cancer does not end once remission is achieved, but instead can become long-term due to lower income level. In Norway, for instance, the income of breast cancer survivors remains significantly lower than controls up to 13 years postdiagnosis, and results in a cumulative income loss of $€ 39,403$ (Šaltytė Benth et al., 2014). Similarly, in the year following diagnosis, Malaysian breast cancer survivors experienced a $21 \%$ income loss (Su et al., 2018) while 37\% of New Zealand cancer survivors, diagnosed within 6 to 24 months and employed at diagnosis, reported a decrease in household income (Bennett et al., 2009). In Canada, cancer survivors earned $\$ 12,240$ less over a 3 year period, which was almost $10 \%$ less than their non-cancer counterparts (Jeon, 2017). Furthermore, Canadian breast cancer survivors experienced a mean wage loss of $\$ 9,311$ in the year following diagnosis (Lauzier et al., 2008). Cancer survivors face substantial income loss, and while it is important to evaluate 


\section{FINANCIAL IMPACT OF CANCER IN YOUNG ADULTS}

whether they are able to cover their expenses, doing so requires an understanding of how much is spent on cancer-related expenses.

\section{Out-of-pocket Health Care Costs}

OOP health care costs create great financial strain among those with chronic conditions, such as cancer. US studies generally reveal that cancer is associated with substantial OOP costs for survivors. Among 159 US cancer survivors, for instance, a median of \$456 per month was spent on OOP cancer-related expenses, excluding indirect costs (Zafar et al., 2013). Breast cancer survivors in the US spent on average \$232.70 per month on OOP costs within the first 3 years of primary treatment completion, and $\$ 186.50$ at quarterly follow ups (Pisu et al., 2017). Furthermore, a 2017 systematic review of 45 studies found that OOP expenses ranged from $\$ 316$ per month among breast cancer survivors to $\$ 741$ per month among the general cancer population (Altice et al., 2017). Cancer survivors, however, tend to pay more OOP expenses than those with other chronic illnesses (Bernard et al., 2011). In the US, for example, 18 to 64 year old cancer survivors are more likely to spend more than $20 \%$ of their income on health expenses compared to those without a chronic condition, and are also more likely to spend more than $20 \%$ of their income compared to those with other chronic conditions (Bernard et al., 2011). Indeed, the high cost of treatment and increasing survivorship may contribute to the high OOP expenses faced by cancer survivors in various countries.

Although a range of expenditure amounts have been reported, all indicate a substantial burden on survivors. Moreover, high financial burden, defined as OOP healthcare expenses exceeding $10 \%$ of family income, can negatively impact health-related quality of life (HRQOL) (Park \& Look, 2018). This link between financial, physical, and psychological health highlights the importance of better understanding how survivors are financially impacted by cancer. 


\section{FINANCIAL IMPACT OF CANCER IN YOUNG ADULTS}

Reducing the financial burden on survivors will likely foster both physical and psychological health benefits.

High OOP costs are not unique to the US and have been found in other countries.

Colorectal cancer survivors in Ireland, who had been diagnosed for at least 6 months and no greater than 30 months, spent an average of $€ 1,589$ on OOP costs (Ó Céilleachair et al., 2017). Similarly, the median OOP expenses accrued over a 2 year post-diagnosis period in Australia were $\mathrm{A} \$ 1,847$ for those with cancer, compared to $\mathrm{A} \$ 936$ and $\mathrm{A} \$ 615$ for a high general practitioner use group and general population, respectively (Gordon et al., 2018). Further, the mean monthly OOP expenses among Korean cancer survivors was 399,300 won (or approximately $\$ 438$ Canadian) (Kim, 2006) and $€ 160.2$ among Italian cancer survivors (Baili et al., 2016).

In Canada, findings on OOP costs among cancer survivors are limited in quantity with mixed results. While prostate cancer survivors 2 to 13 years post-diagnosis spent a mean of $\$ 200$ per year on OOP costs (Oliveira et al., 2014), a sample of Canadian breast, colorectal, lung and prostate cancer survivors spent $\$ 213$ per month on OOP expenses (Longo et al., 2006), which can be financially straining for many Canadian cancer survivors. Cancer type and time since diagnosis may contribute to the variable levels of financial burden survivors face.

In Canada, place of residency may also influence the private OOP costs of cancer treatment, with OOP expenditures in Ontario, and the Atlantic provinces being significantly higher compared to Western Canada (Cancertainty, 2018). Hence, the sense of financial burden associated with a cancer diagnosis may be exacerbated for residents living outside of Western Canada. Similarly, variability in terms of provincial drug plan coverage can also leave patients vulnerable to financial hardship, further embellishing the connection between place of residence 


\section{FINANCIAL IMPACT OF CANCER IN YOUNG ADULTS}

and treatment cost. A 2008 report on issues associated with cancer drug access, for example, found that among couples with average incomes, spending on an oral cancer drug was $\$ 0$ for residents of BC, Alberta, Saskatchewan, Nunavut and the Northwest Territories but was $\$ 20,000$ for residents of New Brunswick and PEI (Turner \& Associates, 2008). The lack of standardization of drug costs may contribute to the geographic disparity of OOP costs and increase the financial cost of cancer for people diagnosed with cancer in certain provinces compared to others.

Canada's population distribution is also a notable mitigating factor when considering the cost of cancer to individuals. In 2011, 18.9\% of Canadians were living in rural areas (Statistics Canada, 2011), and it is these residents who generally face greater OOP travel expenses to access healthcare services (Wong \& Regan, 2009). For example, a patient survey in five Ontario cancer centers found that in addition to costs for medications, medical supplies and care-giver services, patients paid $\$ 372$ related to travel expenditures (Longo et al., 2006). A similar study in Newfoundland and Labrador showed that $34 \%$ of rural cancer patients pay over $\$ 200$ in OOP travel and lodging expenses for a single visit to an oncologist (Mattews, 2001). Patients with fewer financial resources are especially vulnerable to financial hardship due to such travel expenses. It is important to understand this trade-off between cost and follow-up care since Canada has a large rural population requiring travel to access healthcare. As high OOP costs can create a financial strain on cancer survivors, maintaining employment may act as a mechanism for mitigating this burden thus it is important to consider whether (and to what extent) people's employment status and working patterns are affected by having cancer.

\section{Unemployment and Absenteeism}




\section{FINANCIAL IMPACT OF CANCER IN YOUNG ADULTS}

Changes in employment status and absenteeism due to diagnosis and treatment can be especially difficult for cancer survivors because it reduces earnings. Cancer survivors in the US, for example, were more likely to be unemployed compared to those without a history of cancer (Ekwueme et al., 2019). Similarly, in a cohort of 2,892 colorectal, melanoma, Hodgkin lymphoma, non-Hodgkin lymphoma and multiple myeloma survivors in the Netherlands, $27.8 \%$ reported changes to their employment status, and over $30 \%$ of those who reported changes stated they were unable to work due to cancer (Mols et al., 2012). Likewise, among 64 Canadian head and neck cancer survivors who had been employed at the time of diagnosis, $48 \%$ reported a reduction in work following treatment, with almost $33 \%$ of this group indicating they were unable to return to work (Giuliani et al., 2019). Lower workforce participation was also found among 1,117 cancer survivors in the US, where just over 56\% were employed two years prediagnosis compared to more than $72 \%$ of 15,856 respondents who never had cancer. Moreover, employment among cancer survivors fell to just over 50\% two years post-diagnosis (Zajacova et al., 2015). Similarly, unemployment rose from 3\% of 14,678 breast cancer survivors in Denmark 1 week post-diagnosis to $10 \%$ of 11,745 survivors two years after diagnosis (Carlsen et al., 2014). A 2009 meta-analysis found that $33.8 \%$ of cancer survivors were unemployed compared to $15.2 \%$ of controls (de Boer et al., 2009) indicating that cancer creates difficulties in obtaining or maintaining employment; however, since only 2 of 26 studies reviewed were Canadian, less is known about how cancer impacts the employment status of Canadian cancer survivors.

Despite the prevalence of employment changes among cancer survivors, less is known about why employment status changes. Perhaps changing work status may be a reflection of difficulties pertaining to cancer diagnosis and treatment whereby the intensity of treatments received, and consequences of medical interventions including fatigue, anxiety, and pain make it 


\section{FINANCIAL IMPACT OF CANCER IN YOUNG ADULTS}

more difficult for survivors to maintain full-time employment or not miss work. Indeed, a systematic review of breast cancer survivors reported that receiving chemotherapy was a major barrier to returning to work. Radiation and hormone therapy can also negatively impact returning to work (Islam et al., 2014). Cancer-related fatigue is a prevalent problem among $19 \%$ to $38 \%$ of varying cancer populations and can impact cancer survivors both during and up to 10 years posttreatment (Bower et al., 2006; Prue et al., 2006). Cancer-related fatigue is associated with both reduced likelihood of working during treatment and upon returning to work (Pryce et al., 2007). Anxiety is also troublesome for cancer survivors, with $17.9 \%$ of survivors experiencing anxiety compared to $13.9 \%$ of healthy controls (Mitchell et al., 2013). Additionally, anxiety is higher among cancer survivors compared to the general population, with cancer survivors and the general population reporting a mean score of 6.8 and 5.07 out of 21 , respectively on the Hospital Anxiety and Depression Scale (Inhestern et al., 2017). Although this difference is statistically significant, both scores fall within the normal range. Chronic pain is also prevalent among cancer survivors, with $55 \%$ and $39.3 \%$ experiencing pain during and post-treatment, respectively (van Den Beuken-van Everdingen et al., 2016). Moreover, post treatment-related pain has been shown to influence worker retention. In a sample of 2,009 cancer survivors, $86.4 \%$ of 1,404 survivors without chronic neuropathic pain remained employed 5 years post-diagnosis, while only $70.3 \%$ of the 605 survivors who experienced chronic neuropathic pain were employed 5 years postdiagnosis (Alleaume et al., 2018).

Changing work status may also be influenced by survivors' perception of their ability to work. Approximately one quarter of 68 breast cancer survivors who were on average 4.97 years post-treatment perceived their work ability as moderate or poor as measured by the Work Ability Index (WAI) (Von Ah et al., 2017). Survivors' poor perceptions on their work ability could 


\section{FINANCIAL IMPACT OF CANCER IN YOUNG ADULTS}

result in survivors' leaving the workforce prematurely through retirement, sick leave, or longterm disability. Understanding how sick leave and disability programs are utilized among cancer survivors is important due to their impact on earnings. Among 14,750 breast cancer survivors in Denmark, $76 \%$ of those employed one week post-diagnosis were on sick leave, compared to just 13\% who were on sick leave 2 years post-diagnosis (Carlsen et al., 2014). This highlights the importance of understanding the reasons why some people return to work and others do not in order to put appropriate supports in place.

Although many survivors do maintain employment, absenteeism is problematic and can result in financial strain if time off is unpaid. A 2016 systematic review found that cancer survivors reported more absenteeism within 5 years of their diagnosis than their non-cancer peers, having missed 20.7 days in the past year compared to 5.8 days, respectively. However, these differences in absenteeism disappeared when the time from diagnosis exceeded 5 years. Moreover, absenteeism was influenced by type of treatment, with chemotherapy and radiotherapy being risk factors for more absenteeism (Soejima \& Kamibeppu, 2016). This indicates that those diagnosed within 5 years are more susceptible to financial strain caused by missed work.

Each issue discussed above can have a distinct impact on the financial well-being of cancer survivors, but oftentimes the effects are combined. This combined impact is known as financial toxicity.

\section{Financial Toxicity}

Financial toxicity refers to the overall negative economic implications of cancer treatment that burdens patients and their families (Bradley, 2015). The prevalence of financial toxicity among cancer survivors varies widely and depends on the indices used. A 2017 


\section{FINANCIAL IMPACT OF CANCER IN YOUNG ADULTS}

systematic review, for instance, found that financial toxicity has been calculated by the amount spent on OOP costs, amount spent on OOP costs relative to income, cancer survivors' view on tangible solutions to offset the financial burden (e.g., increasing debt or borrowing money), and their perceptions of cancer-related financial burden (Gordon et al., 2017). Financial toxicity was reported among $28 \%$ to $48 \%$ of cancer survivors based on OOP expenses, while $16 \%$ to $73 \%$ reported financial toxicity when asked objective or subjective questions relating to financial toxicity (Gordon et al., 2017). In a US study of 138 bladder cancer survivors, $24 \%$ reported financial toxicity, which was defined as agreeing with or strongly endorsing the statement "you have to pay more for medical care than you can afford". Of those who experienced financial toxicity, 64\% were under age 65 (Casilla-Lennon et al., 2018). Studies using the validated Comprehensive Score for Financial Toxicity (COST) instrument, an 11-item outcome measure describing financial distress experienced by cancer patients (Souza et al., 2014), have shown that financial toxicity is also experienced by metastatic breast cancer survivors in the US (Rosenzweig et al., 2019) and lung cancer survivors in Canada (Ezeife et al., 2019), who report respective median cost values of 23 and 21 . Lower COST scores indicate greater financial toxicity and can range from 0 to 44 (Souza et al., 2014).

Although financial hardship is a stressor among the general population, many cancer survivors report experiencing negative psychological effects because of financial hardship (Yabroff et al., 2016), which demonstrates that the financial and psychological well-being of cancer survivors are intertwined. Improving the financial well-being of cancer survivors may improve psychological outcomes, which consequently could reduce the societal burden of cancer, as well as future financial strain on survivors by promoting their recovery. 


\section{FINANCIAL IMPACT OF CANCER IN YOUNG ADULTS}

The prevalence of psychological financial toxicity differs by age with $31.9 \%$ of those 18 to 64 reporting psychological effects of financial hardship compared to $14.7 \%$ of those 65 and older (Yabroff et al., 2016). The working population may be more vulnerable to this impact because of the enduring effect it can have on their financial future. The prevalence of psychological financial toxicity may be lower among elderly adults because they are less likely to be working, thus job loss and subsequent income loss are less of a concern.

Although financial toxicity is a pervasive problem among all cancer survivors, financial toxicity is particularly relevant to young adults (YAs), defined as those individuals between 15 to 39 years of age (Aubin et al., 2011). YAs are diagnosed at a vulnerable time in their development and will spend the majority of their lives in survivorship, meaning that financial side effects of cancer have the potential to disrupt them to a greater degree than older adults with cancer, or childhood cancer survivors, where the financial burden falls on their parents.

\section{Cancer in Young Adults}

According to recent estimates, of the 206,200 Canadians diagnosed with cancer in 2017 (Canadian Cancer Society's Advisory Committee on Cancer Statistics, 2017), approximately 4\%, or 8,200 were YAs (Canadian Partnership Against Cancer, 2017). When diagnosed as a YA, the disease is usually spontaneous and unrelated to environmental factors (Bleyer, 2007). Moreover, newly diagnosed YAs face both the traditional challenges that accompany a cancer diagnosis, such as acceptance of the diagnosis, dealing with negative treatment side effects, and a fear of cancer recurrence, in addition to a set of challenges that differentiate them from both children and older adults who have been diagnosed with cancer (Kim, 2018). Specific challenges encountered by YA cancer survivors include feeling disconnected from peers, a loss of 


\section{FINANCIAL IMPACT OF CANCER IN YOUNG ADULTS}

independence, treatment effects on fertility, changes in romantic relationships, and educational and career disruption (Geue et al., 2015; Kim, 2018).

Healthcare costs to the public also require special consideration within the context of YA cancer. For example, the net direct medical costs of cancer treatment, defined as the difference between patients with cancer and controls, borne by the public in 2012 dollars was investigated in a cohort of Ontario childhood and adolescent cancer survivors. The net 12-month postdiagnosis medical costs were $\$ 136,413$ for 4,396 children and $\$ 62,326$ for 2,329 adolescents (de Oliveira et al., 2017). Direct medical costs included both inpatient and outpatient services but excluded OOP and time costs (de Oliveira et al., 2017). Despite these substantial costs, between 2005 and 2013, YA-specific cancer research accounted for just $0.4 \%$ of the total cancer research investment (Canadian Partnership Against Cancer, 2017).

\section{Factors that Contribute to the Financial Impact of Cancer in Young Adults}

Educational and Employment Disruption. The developmental transition into young adulthood is typically associated with pursuing post-secondary education, first entry to the labour market, and becoming financially independent from parents. Educational attainment, as well as other economic factors such as YAs' income, assets, and work status are positively associated with financial independence (Xiao et al., 2014). Interruption to education and employment can result in a loss of financial independence and can compromise income, which can compound the financial impact of cancer in YAs.

The impact cancer has on YA independence, both personal and financial, can result in the "failure to launch" phenomenon (Salsman, 2019), which refers to the delay in becoming fully self-sufficient. In the context of YA cancer survivors, failure to launch appears to be inevitable and not a matter of choice. According to YAs in Western societies, reaching adulthood means 


\section{FINANCIAL IMPACT OF CANCER IN YOUNG ADULTS}

accepting responsibility for one's self, making independent decisions, and being financially independent (Kins \& Beyers, 2010). The negative financial implications of suspending educational and career aspirations as a result of a cancer diagnosis can thus inhibit a YA's attainment of self-sufficiency.

The deleterious impact of cancer in YAs on work and education was examined as part of the Adolescent and Young Adult Health Outcomes and Patient Experience (AYA HOPE) study which followed 463 cancer survivors who were 15 to 39 at the time of diagnosis. Of 388 survivors who were working or in school full-time prior to diagnosis, $28 \%$ had not returned to work or school 15 to 35 months post-diagnosis (Parsons et al., 2012). This indicates that a cancer diagnosis in young adulthood can lead to both educational and career disruption. YAs facing education disruption face an additional risk of not being able to graduate from post-secondary institutions. Consequently, these YAs may forfeit financial independence, which is higher among college graduates than those who had never attended college (Xiao et al., 2014). Moreover, YAs whose education is disrupted will likely face a precarious financial situation resulting from postponing entering the labour force and the reduced savings associated with doing so. Educational disruption may also result in YAs not obtaining the qualifications required in the labour market which means that they enter the labour market with a disadvantage or have difficulty entering it at all.

Even YAs who have entered the workforce are at a disadvantage in that they lack the job security possessed by older adults. YAs who survive cancer may also have to re-evaluate education and career goals. In the AYA HOPE study, for instance, over 50\% of all patients working or in school full-time before diagnosis described problems with cognition, such as forgetting, up to 35 months after diagnosis (Parsons et al., 2012). This can be very disruptive and 


\section{FINANCIAL IMPACT OF CANCER IN YOUNG ADULTS}

can affect the financial fate of YA cancer survivors by resulting in the inability to return to school or having to start over in a different field of work. For older adults, it may be less disruptive as seniority can help ease re-entry into the workforce. Understanding whether these findings extend to a Canadian context would help researchers gauge how education disruption influences the financial impact of cancer in YAs.

Unemployment or Underemployment. The uncertainty associated with having to change employment status or even career aspirations can result in higher rates of unemployment among YA cancer survivors. In fact, 20 to 39 year old Canadian cancer survivors were more likely to be unemployed in the past year than the general population (Canadian Partnership Against Cancer, 2017). This has negative implications at both the individual and policy planning level. On a national level, disability and unemployment programs need to consider how to best manage government's fiscal responsibilities with the best interests of YA cancer survivors. This is necessary since these YAs will utilize disability, unemployment or even social assistance programs for longer time periods than both their older counterparts and non-cancer peers.

Higher unemployment rates amongst YA cancer survivors translate to lower personal income, yet even those who remain employed face negative long-term financial impact through reduced earnings. Employed 25 to 39 year old Canadian cancer survivors were more likely than the general population to report having a personal income of less than $\$ 40,000$ (Canadian Partnership Against Cancer, 2017), while the median employment income for full-time workers in Canada was $\$ 51,700$ in 2016 (Statistics Canada, 2016). YA cancer survivors may face greater financial strain than their non-cancer peers due to their income level. The reduced earnings of YA cancer survivors may be a consequence of treatment regimen. Among 141 Canadian survivors who received radiation therapy, for example, significantly lower income was reported 


\section{FINANCIAL IMPACT OF CANCER IN YOUNG ADULTS}

compared to those who received a mix of two or more treatments (Teckle et al., 2018). It was suggested that effects of radiation therapy on the nervous system can contribute to sensory, motor or cognitive deficits that can negatively impact educational and employment achievement (Teckle et al., 2018).

In the US, a 2014 matched comparison sample of 1,464 YA cancer survivors found that they incur additional annual medical expenditures of $\$ 3,170$ per person and spend $\$ 7,417$ annually on medical care, while non-cancer peers spend $\$ 4,247$ (Guy et al., 2014). They also have annual productivity losses of $\$ 2,250$ per person, compared to those without cancer (Guy et al., 2014). This could be a consequence of taking unpaid time off work. The amount of time taken off from work for YA survivors is influenced by both the type of cancer and treatment. In a cross-sectional US sample of 241 breast cancer survivors between 18 and 39 years of age at diagnosis, of whom 209 were employed, chemotherapy exposure was associated with taking 2.62 times more unpaid time off work compared to those who did not receive chemotherapy (Ketterl et al., 2019). Furthermore, among 328 YA survivors of various cancer types, 281were employed, and those exposed to either chemotherapy or radiation were significantly more likely to take unpaid time off and make changes to their hours worked, duties performed, or their employment status compared to those with no chemotherapy or radiation exposure (Ketterl et al., 2019).

In addition to taking more unpaid time off work, chemotherapy exposure has a negative impact on financial stability. Of 736 employed survey respondents who were diagnosed with cancer between 18 and 39 years of age in the US, $1.5 \%$ of the sample reported having filed for bankruptcy as a result of their diagnosis and treatment. Furthermore, those exposed to chemotherapy were significantly more likely to report borrowing $\$ 10,000$ or more compared to survivors not exposed to chemotherapy (Ketterl et al., 2019). 
FINANCIAL IMPACT OF CANCER IN YOUNG ADULTS

\section{Impact of Age on Financial Toxicity within the Young Adult Group}

While the association between financial responsibility and autonomy means that the financial impact of cancer will vary depending on developmental stage, financial responsibility differs even within the young adulthood continuum (Salsman, 2019). For adolescents, the financial burden falls on the family, which could include extended time off work for parents or other financial hardships. YAs in their twenties are transitioning towards independence, and thus are more likely to suffer the financial ramifications of educational disruption (Salsman, 2019). Older YAs are more likely than younger YAs to have established a career, own a home, be in a committed relationship and have children. Consequently, these individuals are most affected by an inability to return to work in order to maintain earnings (Landwehr et al., 2016; Salsman, 2019).

Older YAs are also more likely to report a negative financial impact than younger YAs. Of 524 participants who completed the initial AYA HOPE survey in the US, for example, only $51.4 \%$ of those aged 15 to 20 years reported a negative financial impact, compared to $69.5 \%$ of those aged 21 to 29 and $64.9 \%$ of those aged 30 to 39 (Bellizzi et al., 2012). Further, a retrospective analysis of 334 YA cancer survivors between 19 and 39 years old found that the financial impact of cancer was worse for YAs aged 30 to 39 years compared to those under 30 . This was due to older YAs having more financial responsibilities with less parental assistance (Landwehr et al., 2016). Specifically, the older group had significantly greater total liabilities and monthly expenses than the younger group, as the mean total liabilities for the older group were $\$ 59,012$ US compared to $\$ 37,760$ US for the younger group, while mean monthly expenses were $\$ 2,136$ and \$1,491 US, respectively. Mean total liabilities and mean monthly expenses were approximately $36 \%$ and $30 \%$ less for YAs under 30, respectively, indicating that in addition to 


\section{FINANCIAL IMPACT OF CANCER IN YOUNG ADULTS}

creating financial disparity between survivors and their non-cancer peers, there is significant variability within the YA demographic. Age differences in this sample were attributable to the older group having higher credit card debt and higher likelihood of being homeowners.

More research is needed to assess whether these inequities within the YA demographic are exclusive to the United States or if they exist within Canada. Understanding this disparity in a Canadian context is necessary in order to assess the financial impact of cancer in YAs. Although the financial burden of cancer on YAs has been demonstrated in the US, it is unknown whether this impact extends to YA cancer survivors across Canada due to fundamental differences in healthcare systems, funding of healthcare and availability of insurance.

\section{Financial Impact of Cancer in Canadian Young Adults}

As reviewed above, financial impact is one of the most troublesome and under recognized consequences of a cancer diagnosis in YAs between ages 15 to 39 (Kim, 2018). Most YAs do not have substantial personal savings and no longer have as much parental support (Hartnett et al., 2013). YAs are also likely to still be pursuing their education or be relatively new to the labour market (Clark, 2007), making this a time of financial instability. Financial responsibilities, including childcare costs, student loan and mortgage payments make young adulthood a financially taxing developmental period (Webley et al., 2001). A cancer diagnosis in young adulthood can lead to depleting assets, accruing debt, or declaring bankruptcy.

Consequently, the financial impact of cancer has been suggested to be disproportionally greater for YAs than other age groups (Salsman, 2019).

For Canadian survivors of any age, areas of impact can be difficult to conceptualize under Canada's universal healthcare system. Consequently, Canadians often misconstrue the true cost of healthcare in Canada due to the system's publicly funded structure (Palacios et al., 2018) 


\section{FINANCIAL IMPACT OF CANCER IN YOUNG ADULTS}

which could lead to underestimation of the burden of illness on individuals. This becomes even more complex when geographic landscape is considered. In Canada, for instance, geography has been shown to impact the income of childhood, adolescent and YA cancer survivors up to age 25. Survivors living in small and large communities in BC earned significantly less than those living in larger metropolitan areas (Teckle et al., 2018). Compared to the US and 9 other highincome countries on health care spending, Canada ranked $4^{\text {th }}$ and $5^{\text {th }}$ in regard to unmet health needs among individuals with below-average income (defined as a household income less than $50 \%$ of the country median) and above-average income. Thirty percent of below-average income Canadians indicated that they had: not consulted with a physician; skipped a medical test or follow up; did not fill a prescription; or, missed medication doses because of cost. This compared to $43 \%$ of individuals in the US (Papanicolas et al., 2018). Although difficulty paying medical bills is prevalent in the US, even in Canada, $4.3 \%$ to $5.5 \%$ of general population respondents from 2007 to 2013 had serious problems paying medical bills (Soril et al., 2017). Although comparably less, Canadian respondents still paid \$852 to \$1,767 US OOP for care compared to $\$ 2,060$ to $\$ 3,319$ spent by US respondents (Soril et al., 2017). As such, assessing OOP expenses incurred by cancer survivors would provide the context-specific information needed to propose initiatives aimed at mitigating this impact.

While limited existing Canadian research supports the presence of financial differences among YAs with and without cancer, only one study to date has assessed financial impact provincially (Teckle et al., 2018) and no studies have described the financial impact of cancer for YAs nationally. This initial research suggests that YA cancer survivors are more often unemployed and have lower income than the general population (Canadian Partnership Against Cancer, 2017; Statistics Canada, 2016; Teckle et al., 2018; Wiczer, 2017). Unfortunately, this 


\section{FINANCIAL IMPACT OF CANCER IN YOUNG ADULTS}

research did not separate childhood survivors from YA survivors. Further, it only included survivors up to age 25 , and examined income alone. This approach limits how well the results reflect the reality of YA cancer survivors. Studies are needed to examine the impact of, and recovery from, a cancer diagnosis in the entirety of the YA demographic. The current study addresses these gaps.

\section{Objectives of Current Study}

The objectives of the current study were to identify the financial impact of cancer and assess financial recovery in Canadian YAs. Specifically, I sought to:

1. Assess OOP costs, educational, and occupational impact of cancer in YAs

2. Evaluate current financial impact of cancer in YAs by age compared to matched peers

3. Investigate long-term financial recovery in YAs by time since diagnosis compared to matched peers

Identifying these differences will increase transparency surrounding the age-specific financial hardships faced by YAs and legitimize the prioritization and push for policy changes.

\section{Methods}

\section{Data}

This study used data from the Young Adults with Cancer in their Prime (YACPRIME) survey, a national cross-sectional study of individuals diagnosed with cancer in young adulthood. The YACPRIME study was an online survey that aimed to identify issues for YA cancer survivors. It was conducted in collaboration with a national support and advocacy not-for-profit organization, Young Adult Cancer Canada. Eligibility criteria included receiving a diagnosis of any type or stage of cancer whilst between ages 15 and 39 and being 19 years of age or older at 


\section{FINANCIAL IMPACT OF CANCER IN YOUNG ADULTS}

the time of survey completion. The survey was offered in both English and French. Survey participants were recruited through email, Twitter, Facebook, posters and flyers, the Sleep, Health and Wellness Lab website, word of mouth and personal contacts, or through other channels such as announcements at conferences or through news articles. The survey was initially launched in January 2017 and was closed to recruitment in March 2018, enrolling 622 individuals.

YAs who completed the YACPRIME study were compared to age, sex and educationmatched peers without cancer on financial attributes relating to income, assets and debts from two other cross sectional surveys: the 2014 Canadian Financial Capability Survey (CFCS) and 2014 Canadian Community Health Survey (CCHS) (Statistics Canada, 2014a; Statistics Canada, 2014b). The CFCS provides a benchmark of how Canadians fare on a number of financial wellbeing indicators and assesses Canadians' knowledge, abilities and behaviors in relation to a variety of financial issues. Since raw data for two questions in the CFCS relating to personal and household income were not available, questions pertaining to personal and household income were instead taken directly from the 2014 CCHS. The CCHS is an annual cross-sectional survey conducted by Statistics Canada with the objective of gathering health-related data at the community level.

\section{Measures}

Monthly OOP cancer-related spending (e.g., medications not covered by insurance, travel and accommodations, etc.) and amount of work missed due to cancer diagnosis and treatment were assessed for the YACPRIME sample. Survey questions taken from the CCHS assessed personal and household income using self-reported categorical responses. Level of personal and household income were determined by asking respondents "Could you tell me which of the 


\section{FINANCIAL IMPACT OF CANCER IN YOUNG ADULTS}

following categories best describes your personal income in 2016?" and "Which of the following categories best describes your total household income in 2016?". Response categories included: none or less than $\$ 20,000, \$ 20,000$ to less than $\$ 40,000, \$ 40,000$ to less than $\$ 60,000, \$ 60,000$ to less than $\$ 80,000$, or $\$ 80,000$ or more. Questions adapted from the CFCS assessed the type and value of debts carried and assets owned (see Appendix A).

\section{Statistical Analysis}

Of the 622 individuals recruited for the YACPRIME survey, $92 \%(n=575)$ completed the financial questions and were used in this analysis. The sample was split into two groups, those currently (at the time of survey completion) under 35 and those 35 and older. Since YA survivors were compared to a non-cancer cohort from national Statistics Canada populationbased surveys where variables were categorical, the upper limit of young adulthood (age 39) could not be used to split the sample. Instead, age 35 was chosen as the categorical endpoint that best highlighted differences between YAs and older adults as it captures the majority of the 15 to 39 YA age-range. For time since diagnosis, the YACPRIME sample was split into two groups comprised of those diagnosed within and beyond 5 years. This distinction was chosen to align with the 5 year survival rate that is commonly associated with a cure and is used by researchers and healthcare professionals as a means of determining prognosis and evaluating treatments (American Society of Clinical Oncology, 2020).

Survey data were first analyzed using descriptive statistics to characterize the sample in terms of demographic and clinical variables. Questions relating to monthly OOP cancer-related expenses, amount of work missed, insurance coverage, and type of insurance held could not be directly compared to a non-cancer comparison group since these questions were not asked in the 


\section{FINANCIAL IMPACT OF CANCER IN YOUNG ADULTS}

CCHS or CFCS. These variables could only be described for the YACPRIME sample but are important to consider when evaluating how YAs are financially impacted by cancer.

Case-matching was used to create a comparison sample for each of the analyses. To match YA cancer survivors to their non-cancer peers, the YACPRIME sample was first separated to determine the frequencies of age group, sex, and education status. This was constrained by the categories offered in the CCHS and CFCS surveys. Age groups were: 18-24, 25-34, 35-44, 45-54, 55-59 and 60-64. Sex was broken down into male or female, and education was broken down into four categories (less than secondary, secondary graduate, some postsecondary and post-secondary graduate) in the CCHS and three categories (high school, college and university) in the CFCS.

Using these frequencies, cases from the CCHS and CFCS were randomly sampled in order to create a comparison group consisting of YAs without cancer. Once cases were randomly selected for all age, sex and education frequencies, CCHS and CFCS comparators were separately merged with the YACPRIME dataset to allow for direct comparison between YA cancer survivors and non-cancer peers. Since the YACPRIME survey took exact questions from the CCHS and CFCS, independently merging the comparison group from the CCHS and the comparison group from the CFCS with the YACPRIME dataset enabled direct comparison of income, and type and value of assets owned and debts carried. Using the comparison group randomly sampled from the CCHS, groups were directly compared on both personal and household income. Using the comparison group randomly sampled from the CFCS, groups were directly compared on types of asset and debt ownership, and value of assets and debts. Monetary values were not adjusted for inflation. 
FINANCIAL IMPACT OF CANCER IN YOUNG ADULTS

This case-matching procedure was repeated in order to create an age, sex and education matched comparison group for the following analyses: comparing YA cancer survivors to those without cancer based on current age, and comparing YA cancer survivors to those without cancer based on time since diagnosis. Analyses based on both current age and time since diagnosis were broken down into two comparisons each: YAs 34 years and younger, YAs 35 and older, as well as YAs diagnosed within five years and those diagnosed five or more years ago (see Table 1).

For all analyses, chi square tests of associations were used to compare YA cancer survivors and those without cancer. Fisher's tests were reported instead of chi squares when expected frequencies were less than or equal to five. All analyses were performed using SPSS. The criterion used was $p \leq .05$. Prevalence ratios (PR) were calculated for all findings. PRs are a measure of association often used in cross sectional designs (Martinez et al., 2017) that can illustrate the prevalence of a specific outcome occurring in YA cancer survivors and those without cancer. PRs were used instead of odds ratios (OR) because many of the outcomes analyzed were common in both YA cancer survivors and their non-cancer peers, and ORs can overestimate the strength of the association as rarity decreases (Tamhane et al., 2017). In order to ease interpretation, the reference group for the PR calculations was selected to consistently present PRs greater than 1.0. A PR greater than 1.0 indicates that the outcome prevalence is higher for one group than another. Consequently, in some cases, YA cancer survivors are the reference group whereas in others those without cancer are the reference. The reference group is indicated in all results below.

\section{Results}

\section{YACPRIME Sample Demographics}


FINANCIAL IMPACT OF CANCER IN YOUNG ADULTS

As noted above, the YACPRIME survey only included individuals who had been diagnosed with cancer as a YA and who were at least 19 years of age at the time of the survey. Tables 2 and 3 contain summary statistics for the YACPRIME sample.

All Canadian provinces and territories were included in the survey. Respondents were predominantly English-speaking (92.0\%), Caucasian (88.5\%), female (86.8\%), in relationships (68.7\%), and were working or in school full-time (53.5\%). Approximately $91 \%$ were 25 to 44 years old at the time of survey completion. Almost $6 \%$ were between 18 and 24 and $3.5 \%$ were between 45 and 64. Breast cancer (27.5\%) and blood cancers (27.1\%) were the most commonly reported cancer types, followed by female genitourinary (9.9\%), gastrointestinal (9.4\%), thyroid $(7.7 \%)$, head and neck $(7.7 \%)$, and skin cancer $(3.0 \%)$. Over $6 \%$ reported having multiple or other cancer types. In terms of cancer stage, $13.7 \%$ had stage 1,28.0\% had stage 2, 23.0\% had stage 3 , and $13.7 \%$ had stage 4 cancer. Approximately $60 \%$ were diagnosed within 5 years, and approximately $40 \%$ had been diagnosed for 5 or more years. Of the participants analyzed, $80 \%$ had at least 15 years of education, yet $31.7 \%$ had a personal income under $\$ 20,000$, and only $13.9 \%$ made $\$ 80,000$ or more (see Table 2 ).

\section{Out-of-pocket Costs, Educational, and Occupational Impact}

Overall, 59.7\% of the YACPRIME sample spent at least \$100 per month on OOP cancerrelated expenses. Additionally, $35.4 \%$ of the sample quit work or school completely, while $6.3 \%$ transitioned from full-time to part-time employment or education due to cancer or its treatment. Only $11 \%$ stated that school or employment status did not change due to cancer or its treatment. Moreover, $48.5 \%$ missed at least one year of work (see Table 3).

Financial Impact based on Current Age 
FINANCIAL IMPACT OF CANCER IN YOUNG ADULTS

Financial impact by current age is shown in Table 4 . This presents the results of the comparison of YA cancer survivors to their non-cancer peers for those aged less than 35 years and those 35 years of age and older, separately.

\section{Income}

Compared to non-cancer peers from the CCHS, YA cancer survivors under 35 did not differ significantly in level of personal or household income. Similarly, survivors 35 and older did not significantly differ from their non-cancer peers in terms of personal or household income (see Table 4).

\section{Value and Type of Debts Carried}

For those under 35 years of age, there was a significant difference in the value of debts between YA cancer survivors and their non-cancer peers from the CFCS $(p<.001)$. YAs under 35 without cancer were more likely to have a mortgage than YA cancer survivors ( $\mathrm{PR}=1.23$ $[1.05,1.44], p=.011)$. In contrast, YA cancer survivors under 35 were significantly more likely to have payday loans $(\mathrm{PR}=5.37[1.20,24.0], p=.013)$, outstanding credit card balances $(\mathrm{PR}=$ $1.37[1.13,1.67], p=.001)$, and outstanding line of credit $(\mathrm{LOC})$ balances $(\mathrm{PR}=1.42[1.09$, $1.85], p=.008)$. YA cancer survivors 35 and older were significantly more likely than their noncancer peers to have student loans ( $\mathrm{PR}=1.88[1.25,2.81], p=.002)$, outstanding credit card balances $(\mathrm{PR}=1.33[1.11,1.59], p=.001)$, and outstanding LOC balances $(\mathrm{PR}=1.27$ [1.04, $1.54], p=.016)$.

\section{Value and Type of Assets Owned}

YA cancer survivors under $35(p=.002)$ and those 35 and older $(p<.001)$ significantly differed in the value of their assets compared to their respective non-cancer peers from the CFCS. A higher percentage of YA cancer survivors under 35 had no assets compared to their 
FINANCIAL IMPACT OF CANCER IN YOUNG ADULTS

non-cancer peers $(\mathrm{PR}=2.48[1.64,3.76], p<.001)$. In contrast, those without cancer had higher rates of home $(\mathrm{PR}=1.42[1.20,1.68], p<.001)$ and vehicle ownership $(\mathrm{PR}=2.40[1.67,3.46], p$ $<.001)$. Those 35 and older without cancer were also more likely to own a home $(\mathrm{PR}=1.69$ $[1.26,2.25], p<.001)$ or vehicle $(\mathrm{PR}=1.92[1.20,3.07], p=.005)$, compared to cancer survivors.

\section{Financial Recovery based on Time Since Diagnosis}

The comparisons of YA cancer survivors and their non-cancer peers by time since diagnosis are shown in Table 5. These comparisons help illustrate the degree of financial recovery experienced by YA cancer survivors.

\section{Income}

When those diagnosed within 5 years were compared to their non-cancer peers from the CCHS, personal income significantly differed between groups $\left(\chi^{2}(4)=10.127, p=.038\right)$. No statistical differences in personal income were found among those diagnosed 5+ years ago and their non-cancer peers. Household income did not statistically differ between YA cancer survivors and those without cancer, regardless of time since diagnosis.

\section{Value and Type of Debts Carried}

Those diagnosed both within $(p=.005)$ and beyond 5 years $(p=.003)$ significantly differed in the value of their debts, compared to their respective non-cancer peers from the CFCS. Those without cancer were more likely to have a mortgage than YAs diagnosed with cancer for $5+$ years $(\mathrm{PR}=1.25[1.01,1.55], p=.036)$. In contrast, YAs diagnosed within 5 years were significantly more likely to have payday loans $(\mathrm{PR}=3.91[1.11,13.71], p=.021)$, outstanding credit card balances $(\mathrm{PR}=1.21[1.03,1.43], \mathrm{p}=.023)$ and outstanding LOC balances $(\mathrm{PR}=1.23[1.00,1.50], p=.044)$, compared to non-cancer peers. YAs diagnosed for 


\section{FINANCIAL IMPACT OF CANCER IN YOUNG ADULTS}

$5+$ years were still significantly more likely than their non-cancer peers to have outstanding credit card $(\mathrm{PR}=1.49[1.21,1.84], p<.001)$ and LOC balances $(\mathrm{PR}=1.31[1.03,1.66], p=$ $.029)$ and were more likely to have student loans ( $\mathrm{PR}=1.42[1.00,2.01], p=.049)$.

\section{Value and Type of Assets Owned}

Those diagnosed both within $(p=.002)$ and beyond 5 years $(p<.001)$ significantly differed in the value of their assets compared to their respective non-cancer peers from the CFCS. A greater percentage of YAs diagnosed within 5 years had no assets compared to their non-cancer peers $(\mathrm{PR}=2.25[1.47,3.44], p<.001)$. In contrast, those without cancer had higher rates of home $(\mathrm{PR}=1.39[1.16,1.66], p<.001)$ and vehicle ownership $(\mathrm{PR}=2.17[1.52,3.08], p$ $<.001)$ compared to those diagnosed within 5 years. Those without cancer also had greater likelihood of home $(\mathrm{PR}=1.41[1.10,1.80], p=.005)$ and vehicle ownership $(\mathrm{PR}=1.94[1.22$, $3.09], p=.004)$ compared to those diagnosed for $5+$ years.

\section{Discussion}

Evaluating the financial impact of cancer is challenging considering the breadth of areas in which cancer survivors can be affected. The lack of research focused on the YA population only further complicates this challenge. This is the first Canadian study to assess financial impact and recovery in a large sample of Canadians diagnosed with cancer in young adulthood. This study provides vital information on the financial health of YA cancer survivors compared to their non-cancer peers in terms of income, debts and assets. This study also presents the amount of OOP expenses incurred by YA cancer survivors and the amount of work missed. Overall, the results demonstrate that although YA cancer survivors can keep up with their non-cancer counterparts in terms of income, they are financially worse off than their non-cancer peers in many ways. Specifically, YA cancer survivors face unique challenges in terms of OOP costs and 


\section{FINANCIAL IMPACT OF CANCER IN YOUNG ADULTS}

missed work. They also incur more debt, such as credit cards and LOCs, and own less assets, such as homes and vehicles, compared to YAs without cancer.

\section{Challenges Specific to Young Adult Cancer Survivors}

Many hardships associated with cancer occur in the survivorship phase (Feuerstein, 2007). The high survivorship of cancer, which is approximately $60 \%$ over five years, has also resulted in additional financial challenges for patients and their families (Canadian Institute for Health Information, 2014). The current study found that almost $60 \%$ of the sample reported spending at least $\$ 100$ per month on cancer-related OOP expenses. This can create many challenges for YAs, especially since Canadian YAs have lower median income compared to older adults (Statistics Canada, 2020). In the US, YA survivors report spending approximately \$210 per month on medical expenses (Landwehr et al., 2016). However, direct comparison between the current study and US research is difficult since the current study relied on categorical data, whereas the comparison study used continuous data.

High OOP expenses become even more problematic when considering the amount of work missed by YA cancer survivors. The current study found that almost half the sample missed at least one year of work, which complements findings from a 2017 systematic review out of the US which noted that adult survivors of YA cancer experienced almost double the productivity losses of adults without a history of cancer (Altice et al., 2017; Guy et al., 2014). Furthermore, over $14 \%$ of this Canadian sample missed at least 3 years of work, which aligns with US research showing that YA cancer survivors experience career disruption up to 35 months post-diagnosis (Parsons et al., 2012). This is very alarming given that YAs are not nearing retirement age, unlike their older counterparts. Productivity losses and time off among 
FINANCIAL IMPACT OF CANCER IN YOUNG ADULTS

this group of survivors can add strain to Canada's disability and employment insurance programs from those who are too young to draw a pension but are unable to work.

\section{Areas Where Young Adult Cancer Survivors are Comparable to Non-cancer Peers}

Despite the financial challenges YAs face (Bleyer et al., 2007), they are on par with their non-cancer peers in terms of income, with the exception of those diagnosed within 5 years. This may be due in part to the sample being highly educated, with $80 \%$ reporting at least 15 years of education. Within Canada's general population, educational attainment is consistently associated with higher income (Lemieux, 2001). Income differences between YA cancer survivors and agematched peers have been found in the US, where YA cancer survivors were found to have lower median income (Landwehr et al., 2016); however, one caveat to this US study is that the education level of the sample was unknown. The sample's education level may be lower than that of the Canadian YACPRIME sample. However, support for post-secondary education in terms of enrollment is higher in Canada, compared to other countries like the US (Frenette, 2005), which may allow for greater educational attainment and reduction of income disparities between cancer survivors and those without cancer. Employment among survivors increases with increasing time since diagnosis (Mehnert, 2011), which may also account for why there are income differences among YAs diagnosed within 5 years but not those diagnosed for 5 or more years. Although this is a positive sign, the negative impact, and subsequent inability to fully recover in other areas such as asset ownership and debt carried, highlight both the magnitude and enduring nature of the financial impact of cancer on YAs.

\section{Areas where Young Adult Cancer Survivors are Not Comparable to Non-cancer Peers}

The financial impact of cancer in young adulthood is devastating in important areas, such as debt load and asset accumulation. Further, there is no evidence of recovery in terms of credit 


\section{FINANCIAL IMPACT OF CANCER IN YOUNG ADULTS}

card and LOC debt, home and vehicle ownership, and value of assets. It appears that YA cancer survivors do not catch up to their non-cancer peers in these areas, regardless of current age or time since diagnosis.

Younger YA cancer survivors ( $<35$ years) are especially disadvantaged compared to those unaffected by cancer in areas like mortgage ownership, debt level, and asset acquisition. This is not surprising given that younger age is associated with greater financial toxicity in Canadian lung cancer survivors (Ezeife et al., 2019) and may be a consequence of reduced likelihood of employment prior to diagnosis among younger YAs (Quintini \& Martin, 2006). Those with cancer also reported less debt than their non-cancer counterparts, irrespective of time since diagnosis; however, certain debts such as taking out mortgages, can be expected in young adulthood and actually indicate financial independence. From a lifespan perspective, this debt disparity further underscores the longevity of the financial impact of cancer in YAs.

Additionally, compared to non-cancer peers, acquiring assets is problematic for YAs under 35, but not for those 35 and older, and persists with increasing time since diagnosis. This suggests that receiving a cancer diagnosis contributes to financial hardship in YAs and this impact persists long into survivorship.

Older YA cancer survivors ( $\geq 35$ years) are more likely to have student loan debt compared to non-cancer peers. Conversely, although the prevalence of student loan debt is higher among younger YAs ( $<35$ years), there is no statistical difference between cancer survivors and those without cancer. This is not surprising considering that younger YAs are more likely to still be completing their education and have not yet started paying down student loan debt. The difference becomes apparent among those 35 and older, who are more likely to have started making payments on student loan debt. It seems that older YA cancer survivors do not 


\section{FINANCIAL IMPACT OF CANCER IN YOUNG ADULTS}

have the means to repay student loan debt, and thus are almost twice as likely as their non-cancer peers to report having student loan debt.

Greater monthly OOP cancer-related expenses are incurred by YAs diagnosed within 5 years; thus, the immediacy of payday loans may seem attractive to cover their expenses. In the US, individuals frequently use payday loans as a means of medical bill payment (Bickham \& Lim, 2015). Despite systemic differences in healthcare systems between the US and Canada, Canadian YA cancer survivors under 35, and those diagnosed within 5 years still face this hardship. Federal assistance programs specific to cancer care are not available in Canada. Some YAs may have private coverage for sick leave, short and long-term disability but only if they, or their employer, have been paying into this benefit. The substantial time off that YA cancer survivors require is often not covered by Employment Insurance sick benefits. This may underlie why many YA cancer survivors quit work or school or move to part-time status and may contribute to the perpetuation of financial challenges beyond young adulthood.

\section{Psychological Considerations}

Large US studies of adult cancer survivors have found that experiencing cancer-related financial burden is a strong predictor of poor quality of life (Fenn et al., 2014; Kale \& Carroll, 2016). Financial stress can also impact the psychological well-being of survivors. For example, the struggle to keep up with others in these areas could worsen or re-trigger post-traumatic stress symptoms in YAs with post-traumatic stress disorder (PTSD), a disorder that can be considered common among YAs in general (Breslau et al., 1991) and among YA survivors of childhood cancer (Hobbie et al., 2000; Schwartz \& Drotar, 2006). Experiencing financial stress due to cancer may cause survivors to re-experience traumatic events in the same way that an upcoming scan or scar can. Although not specific to survivors diagnosed with cancer in young adulthood, 


\section{FINANCIAL IMPACT OF CANCER IN YOUNG ADULTS}

risk of depression was also almost 3 times higher, and risk of anxiety over 3 times higher among cancer survivors who reported increased cancer-related financial stress (Sharp et al., 2013). These associations highlight the importance of understanding how YA cancer survivors are financially impacted by cancer, and also demonstrate the need for a holistic approach when attempting to reduce inequities. Doing so is a first step in determining where improvement efforts should be focused. It can also assist in determining which YAs may benefit most from psychosocial intervention.

\section{Limitations and Future Research}

Despite concerted recruitment efforts, males were underrepresented in the YACPRIME sample which may limit the generalizability of findings. Second, the financial indices used in the study were self-report, which can influence measurement precision and response accuracy. However, these questions were selected from national surveys deemed appropriate to assess financial health at a population level. Third, it was not possible to compare YAs based on age at diagnosis because those without cancer could not be matched on this attribute. Instead, current age was used to indicate how cancer survivors and those without cancer differed by age. Finally, comparisons using 2014 dollars were not inflation-adjusted, but this potential influence on results was limited through the use of wide categorical ranges.

Despite these limitations, this study provides the first Canadian estimates into the financial impact of cancer for YAs. Future research is needed to better understand why YA cancer survivors are especially vulnerable to hardship specific to debt load and asset accumulation but not income. Previous Canadian research has shown an average wage loss of $\$ 4,518$ among cancer patients; however, this was not specific to YAs (Hopkins et al., 2010). The current findings may be a consequence of reduced career stability among YAs prior to diagnosis. 


\section{FINANCIAL IMPACT OF CANCER IN YOUNG ADULTS}

A better understanding of wage loss among YAs could guide advocacy efforts for this underserved population. Similar to the US, there is a negative financial impact for YA cancer survivors in Canada, despite falling under a universal healthcare system. However, since many Canadians have trouble paying medical debt (Soril et al., 2017), future research should compare these findings to US samples, where many YAs may have little or no insurance coverage. Studies designed to specifically evaluate financial recovery in YA cancer survivors could also help further define areas where assistance is needed and aid in the development of appropriately targeted interventions.

\section{Recommendations for Policy Change and Support Interventions}

Our findings should serve as a call to action to policy makers to introduce resources to assist those facing financial burden due to cancer, since few Canadian resources currently exist. In Canada, employed cancer survivors can avail of Employment Insurance sick benefits, which only allow a maximum of 15 weeks coverage (Léonard, 2010). Following this, survivors can apply for the Canada Pension Plan disability benefit. However, these programs are meant to partially replace income for those not working and who are unable to return to work. One eligibility requirement for Canada's disability benefit is that applicants need to have made contributions to the Canada Pension Plan in 4 of the last 6 years (Government of Canada, 2020), which for YAs may be difficult to achieve. A US study of 647 cancer survivors age 55 to 65 that were 2 to 6 years post-diagnosis found disability rates to be almost twice that of adults without a chronic condition (Short et al., 2008). However, since the current pathway available to Canadian cancer survivors does not seem amenable to incorporate the YA population, funding programs that can have a direct and immediate benefit on YA survivors are needed. 


\section{FINANCIAL IMPACT OF CANCER IN YOUNG ADULTS}

It is important to develop programs specifically aimed at reducing OOP expenses and work missed. These initiatives may reduce the income disparity among those diagnosed within 5 years, the reliance on credit card and LOC debt, and consequently reduce the severity and permanency of the financial impact of cancer and promote financial recovery in YAs. Improving coverage and consistency among current provincial drug plans may be one way to help alleviate this burden. This may be more effective than implementing return to work initiatives. In a 2010 systematic review of 19 studies from the US, Scandinavia, the Netherlands, Germany and the United Kingdom that evaluated return to work interventions in cancer survivors, of which 4 were controlled, only 1 controlled study found a significant increase in return to work while 3 controlled studies found no significant differences (Tamminga et al., 2010). However, rehabilitation programs may be a cost-effective option for specific malignancies such as breast cancer, since Canadian breast cancer survivors with range of motion or arm pain are more than 2.5 times more likely to lose productivity capacity compared to survivors without these issues (Quinlan et al., 2009). Although the cost of implementing rehabilitation programs may be offset by improvements in productivity, resources may be better spent on reducing costs that are shouldered by survivors. This may also reduce financial stress, which is associated with lower quality of life among adult survivors (Fenn et al., 2014; Lu et al., 2019). Despite this, no studies to date have directly assessed whether psychological support can promote financial recovery; however, one US study of 1,209 cancer survivors found that those with good, fair or poor health status were almost 4 times more likely to report financial difficulties compared to those reporting excellent or very good health status (Whitney et al., 2016). As such, efforts to improve health status or reduce the financial challenges may have positive downstream impacts and reduce the overall burden facing YA cancer survivors. 
FINANCIAL IMPACT OF CANCER IN YOUNG ADULTS

\section{Conclusions}

YA cancer survivors are both understudied (Canadian Partnership Against Cancer, 2017) and underserved, despite being a survivorship group with unique needs. This is the first national survey to assess the financial impact of cancer in this group and helps fill an important literature gap. The current study reveals that Canadian YAs are not immune to the financial toll of cancer that is evident in the US (Guy et al., 2014; Parsons et al., 2012). It also identifies areas where YA cancer survivors are likely to experience negative financial impact. This study lends support to ratifying Canada's Employment Insurance program and provincial drug coverage programs to better fit the needs of working-age cancer survivors. Moving forward, survivorship care plans for YA cancer survivors should incorporate psychosocial supports and education on the financial impact of cancer. This is necessary since many of the financial side effects of cancer persist beyond diagnosis and treatment. 
FINANCIAL IMPACT OF CANCER IN YOUNG ADULTS

\section{References}

Alleaume, C., Bendiane, M.-K., Bouhnik, A.-D., Rey, D., Cortaredona, S., Seror, V., \& PerettiWatel, P. (2018). Chronic neuropathic pain negatively associated with employment retention of cancer survivors: evidence from a national French survey. Research and Practice, 12(1), 115-126. https://doi.org/10.1007/s11764-017-0650-z

Altice, C. K., Banegas, M. P., Tucker-Seeley, R. D., \& Yabroff, K. R. (2017). Financial Hardships Experienced by Cancer Survivors: A Systematic Review. Journal of the National Cancer Institute, 109(2), 1-17. https://doi.org/10.1093/jnci/djw205

American Society for Clinical Oncology. (2020, March). Understanding Statistics Used to Guide Prognosis and Evaluate Treatment. https://www.cancer.net/navigating-cancercare/cancer-basics/understanding-statistics-used-guide-prognosis-and-evaluate-treatment.

Aubin, S., Barr, R., Rogers, P., Schacter, B., Bielack, S. S., Ferrari, A., Manchester, R., McMaster, K., Morgan, S., Patterson, M., Petrilli, A., Ribera, J., Shaw, P., Thomas, D. M., \& Treadgold, C. (2011). What Should the Age Range Be for AYA Oncology? Journal of adolescent and young adult oncology, 1(1), 3-10. https://doi.org/10.1089/jayao.2011.1505

Baili, P., Salvo, F., Lorenzo, F., Maietta, F., Pinto, C., Rizzotto, V., Vicentini, M., Rossi, P., Tumino, R., Rollo, P., Tagliabue, G., Contiero, P., Candela, P., Scuderi, T., Iannelli, E., Cascinu, S., Aurora, F., Agresti, R., Turco, A., Sant, M., Meneghini, E., \& Micheli, A. (2016). Out-of-pocket costs for cancer survivors between 5 and 10 years from diagnosis: an Italian population-based study. Supportive Care in Cancer, 24(5), 2225-2233. https://doi.org/10.1007/s00520-015-3019-8 


\section{FINANCIAL IMPACT OF CANCER IN YOUNG ADULTS}

Bellizzi, K. M., Smith, A., Schmidt, S., Keegan, T. H. M., Zebrack, B., Lynch, C. F., Deapen, D., Shnorhavorian, M., Tompkins, B. J., \& Simon, M. (2012). Positive and negative psychosocial impact of being diagnosed with cancer as an adolescent or young adult. Cancer, 118(20), 5155-5162. https://doi.org/10.1002/cncr.27512

Bennett, J., Brown, P., Cameron, L., Whitehead, L., Porter, D., \& McPherson, K. (2009). Changes in employment and household income during the 24 months following a cancer diagnosis. Supportive Care in Cancer, 17(8), 1057-1064. https://doi.org/10.1007/s00520$\underline{008-0540-z}$

Bernard, D. S. M., Farr, S. L., \& Fang, Z. (2011). National estimates of out-of-pocket health care expenditure burdens among nonelderly adults with cancer: 2001 to 2008. Journal of clinical oncology : official journal of the American Society of Clinical Oncology, 29(20), 2821-2826. https://doi.org/10.1200/JCO.2010.33.0522

Bickham, T., \& Lim, Y. (2015). In Sickness and in Debt: Do Mounting Medical Bills Predict Payday Loan Debt? Social Work in Health Care, 54(6), 518-531. https://doi.org/10.1080/00981389.2015.1038410

Bleyer, A. (2007). Young Adult Oncology: The Patients and Their Survival Challenges. $C A$ : $A$ Cancer Journal for Clinicians, 57(4), 242-255. https://doi.org/10.3322/canjclin.57.4.242

Bleyer, W. A., Barr, R. D., \& SpringerLink. (2007). Cancer in Adolescents and Young Adults. Berlin, Heidelberg : Springer Berlin Heidelberg.

Bower, J. E., Ganz, P. A., Desmond, K. A., Bernaards, C., Rowland, J. H., Meyerowitz, B. E., \& Belin, T. R. (2006). Fatigue in long-term breast carcinoma survivors: A longitudinal investigation. Cancer, 106(4), 751-758. https://doi.org/10.1002/cncr.21671 


\section{FINANCIAL IMPACT OF CANCER IN YOUNG ADULTS}

Bradley, C. J. (2015). Economic recovery: A measure of the quality of cancer treatment and survivorship? Cancer, 121(24), 4282-4285. https://doi.org/10.1002/cncr.29511

Breslau, N., Davis, G., Andreski, P., \& Peterson, E. (1991). Traumatic events and posttraumatic stress disorder in an urban population of young adults. Archives of General Psychiatry, 48(3), 216-222. https://doi.org/10.1001/archpsyc.1991.01810270028003

Canadian Cancer Society's Advisory Committee on Cancer Statistics. (2017). Canadian Cancer Statistics 2017. cancer.ca/Canadian-Cancer-Statistics-2017-EN.pdf

Canadian Electronic Library, d. (2016). Payday Loans : Market Trends. Ottawa, ON, CA: Financial Consumer Agency of Canada.

Canadian Institute for Health Information. (2014). National health expenditure trends, 1975 to 2013.

Canadian Partnership Against Cancer. (2017). Adolescents \& Young Adults with Cancer: A System Performance Report.

Cancertainty. (2018). FAQ. http://www.cancertaintyforall.ca/faq

Carlsen, K., Ewertz, M., Dalton, S. O., Badsberg, J. H., \& Osler, M. (2014). Unemployment among breast cancer survivors. Scandinavian Journal of Public Health, 42(3), 319-328. https://oi.org/10.1177/1403494813520354

Casilla-Lennon, M. M., Choi, S. K., Deal, A. M., Bensen, J. T., Narang, G., Filippou, P., McCormick, B., Pruthi, R., Wallen, E., Tan, H.-J., Woods, M., Nielsen, M., \& Smith, A. (2018). Financial Toxicity among Patients with Bladder Cancer: Reasons for Delay in Care and Effect on Quality of Life. The Journal of Urology, 199(5), 1166-1173.

https://doi.org/10.1016/j.juro.2017.10.049

Clark, W. (2007). Delayed transitions of young adults. Canadian Social Trends, 84, 14-22. 


\section{FINANCIAL IMPACT OF CANCER IN YOUNG ADULTS}

de Boer, A. G. E. M., Taskila, T., Ojajärvi, A., van Dijk, F. J. H., \& Verbeek, J. H. A. M. (2009). Cancer Survivors and Unemployment A Meta-analysis and Meta-regression. JAMA, 301(7), 753-762. https://doi.org/10.1001/jama.2009.187

de Oliveira, C., Bremner, K. E., Liu, N., Greenberg, M. L., Nathan, P. C., McBride, M. L., \& Krahn, M. D. (2017). Costs for Childhood and Adolescent Cancer, 90 Days Prediagnosis and 1 Year Postdiagnosis: A Population-Based Study in Ontario, Canada. Value in health., 20(3), 345-356. https://doi.org/10.1016/j.jval.2016.10.010

de Oliveira, C., Weir, S., Rangrej, J., Krahn, M. D., Mittmann, N., Hoch, J. S., Chan, K. K. W., \& Peacock, S. (2018). The economic burden of cancer care in Canada: a populationbased cost study. CMAJ Open, 6(1), E1-E10. https://doi.org/10.9778/cmajo.20170144 Diener, A., Dugas, J., Eng, K., \& Canadian Electronic Library, d. (2018). Economic Burden of Illness in Canada, 2010 : Protecting and Empowering Canadians to Improve Their Health. Ottawa, ON, CA: Public Health Agency of Canada.

Ekwueme, D. U., Zhao, J., Rim, S. H., de Moor, J. S., Zheng, Z., Khushalani, J. S., Han, X., Kent, E. E., \& Yabroff, K. R. (2019). Annual Out-of-Pocket Expenditures and Financial Hardship Among Cancer Survivors Aged 18-64 Years - United States, 2011-2016. MMWR Morb Mortal Wkly Rep, 68(22), 494-499. https://doi.org/10.15585/mmwr.mm6822a2

Ezeife, D. A., Morganstein, B. J., Lau, S., Law, J. H., Le, L. W., Bredle, J., Cella, D., Doherty, M. K., Bradbury, P., Liu, G., Sacher, A., Shepherd, F. A., \& Leighl, N. B. (2019). Financial Burden Among Patients With Lung Cancer in a Publically Funded Health Care System. Clinical Lung Cancer, 20(4), 231-236. https://doi.org/10.1016/j.cllc.2018.12.010 


\section{FINANCIAL IMPACT OF CANCER IN YOUNG ADULTS}

Fenn, K. M., Evans, S. B., McCorkle, R., Digiovanna, M. P., Pusztai, L., Sanft, T., Hofstatter, E. W., Killelea, B. K., Knobf, M. T., Lannin, D. R., Abu-Khalaf, M., Horowitz, N. R., \& Chagpar, A. B. (2014). Impact of financial burden of cancer on survivors' quality of life. Journal of oncology practice, 10(5), 332. https://doi.org/10.1200/JOP.2013.001322

Feuerstein, M. (2007). The Burden of Cancer Survivorship. Boston, MA: Springer US. https://doi.org/10.1007/978-0-387-34562-8_2

Frenette, M. (2005). Is post-secondary access more equitable in Canada or the United States? Ottawa : Statistics Canada, Analytical Studies.

Geue, K., Schmidt, R., Sender, A., Sauter, S., \& Friedrich, M. (2015). Sexuality and romantic relationships in young adult cancer survivors: satisfaction and supportive care needs: Sexuality and romantic relationships of AYA. Psycho-Oncology, 24(11), 1368-1376. https://doi.org/10.1002/pon.3805

Giuliani, M., Papadakos, J., Broadhurst, M., Jones, J., McQuestion, M., Le, L. W., Beck, L., Waldron, J., \& Ringash, J. (2019). The prevalence and determinants of return to work in head and neck cancer survivors. Support Care Cancer, 27(2), 539-546. https://doi.org/10.1007/s00520-018-4343-6

Gordon, L., Merollini, K., Lowe, A., \& Chan, R. (2017). A Systematic Review of Financial Toxicity Among Cancer Survivors: We Can't Pay the Co-Pay. The Patient - PatientCentered Outcomes Research, 10(3), 295-309. https://doi.org/10.1007/s40271-016-0204$\underline{\mathrm{x}}$

Gordon, L. G., Elliott, T. M., Olsen, C. M., Pandeya, N., \& Whiteman, D. C. (2018). Patient outof-pocket medical expenses over 2 years among Queenslanders with and without a major 
FINANCIAL IMPACT OF CANCER IN YOUNG ADULTS

cancer. Australian Journal of Primary Health, 24(6), 530-536.

https://doi.org/10.1071/PY18003

Government of Canada. (2020). The Canada Pension Plan Disability Benefits.

https://www.canada.ca/en/employment-social-development/programs/pension-plandisability-benefits.html

Guy, G. P., Ekwueme, D. U., Yabroff, K. R., Dowling, E. C., Li, C., Rodriguez, J. L., de Moor, J. S., \& Virgo, K. S. (2013). Economic burden of cancer survivorship among adults in the United States. Journal of clinical oncology : official journal of the American Society of Clinical Oncology, 31(30), 3749. https://doi.org/10.1200/JCO.2013.49.1241

Guy, G. P., Yabroff, K. R., Ekwueme, D. U., Smith, A. W., Dowling, E. C., Rechis, R., Nutt, S., \& Richardson, L. C. (2014). Estimating the health and economic burden of cancer among those diagnosed as adolescents and young adults. Health affairs (Project Hope), 33(6), 1024-1031. https://doi.org/10.1377/hlthaff.2013.1425

Hartnett, C. S., Furstenberg, F. F., Birditt, K. S., \& Fingerman, K. L. (2013). Parental Support During Young Adulthood: Why Does Assistance Decline With Age? Journal of Family Issues, 34(7), 975-1007. https://doi.org/10.1177/0192513X12454657

Hobbie, W. L., Stuber, M., Meeske, K., Wissler, K., Rourke, M. T., Ruccione, K., Hinkle, A., \& Kazak, A. E. (2000). Symptoms of posttraumatic stress in young adult survivors of childhood cancer. Journal of clinical oncology : official journal of the American Society of Clinical Oncology, 18(24), 4060. https://doi.org/10.1200/JCO.2000.18.24.4060

Hopkins, R. B., Goeree, R., \& Longo, C. J. (2010). Estimating the national wage loss from cancer in Canada. Current oncology (Toronto, Ont.), 17(2), 40-49.

https://doi.org/10.3747/co.v17i2.477 


\section{FINANCIAL IMPACT OF CANCER IN YOUNG ADULTS}

Inhestern, L., Beierlein, V., Bultmann, J., Moller, B., Romer, G., Koch, U., \& Bergelt, C. (2017). Anxiety and depression in working-age cancer survivors: a register-based study. $B M C$ Cancer, 17(1). https://doi.org/10.1186/s12885-017-3347-9

Islam, T., Dahlui, M., Majid, H. A., Nahar, A. M., Mohd Taib, N. A., \& Su, T. T. (2014). Factors associated with return to work of breast cancer survivors: a systematic review. $B M C$ Public Health, 14(Suppl 3), S8-S8. https://doi.org/10.1186/1471-2458-14-S3-S8

Jeon, S. H. (2017). The Long-Term Effects of Cancer on Employment and Earnings. Health Economics, 26(5), 671-684. https://doi.org/10.1002/hec.3342

Kale, H. P., \& Carroll, N. V. (2016). Self- reported financial burden of cancer care and its effect on physical and mental health- related quality of life among US cancer survivors. Cancer, 122(8), 283-289. https://doi.org/10.1002/cncr.29808

Ketterl, T. G., Syrjala, K. L., Casillas, J., Jacobs, L. A., Palmer, S. C., McCabe, M. S., Ganz, P. A., Overholser, L., Partridge, A., Rajotte, E. J., Rosenberg, A. R., Risendal, B., Rosenstein, D. L., \& Baker, K. S. (2019). Lasting effects of cancer and its treatment on employment and finances in adolescent and young adult cancer survivors. Cancer, 125(11). https://doi.org/10.1002/cncr.31985

Kim, B., Patterson, P., \& White, K. (2018). Developmental considerations of young people with cancer transitioning to adulthood. European Journal of Cancer Care, 27(6). https://doi.org/10.1111/ecc.12836

Kim, S. G., Park, W.S. (2006). Out-of-pocket health expenditures among adult Koreans with cancer. The Korean Journal of Medicine, 70(1), 61-68. 


\section{FINANCIAL IMPACT OF CANCER IN YOUNG ADULTS}

Kins, E., \& Beyers, W. (2010). Failure to Launch, Failure to Achieve Criteria for Adulthood? Journal of Adolescent Research, 25(5), 743-777. https://doi.org/10.1177/0743558410371126

Landwehr, M. S., Watson, S. E., Macpherson, C. F., Novak, K. A., \& Johnson, R. H. (2016). The cost of cancer: a retrospective analysis of the financial impact of cancer on young adults. Cancer Med, 5(5), 863-870. https://doi.org/10.1002/cam4.657

Lauzier, S., Maunsell, E., Drolet, M., Coyle, D., Hébert-Croteau, N., Brisson, J., Mâsse, B., Abdous, B., Robidoux, A., \& Robert, J. (2008). Wage Losses in the Year After Breast Cancer: Extent and Determinants Among Canadian Women. Journal of the National Cancer Institute, 100(5), 321-332. https://doi.org/10.1093/jnci/djn028

Lawrence, E. C., \& Elliehausen, G. (2008). A COMPARATIVE ANALYSIS OF PAYDAY LOAN CUSTOMERS. Contemporary Economic Policy, 26(2), 299-316. https://doi.org/10.1111/j.1465-7287.2007.00068.x

Lemieux, T. (2001). The causal effect of education on earnings in Canada. Department of Economics, University of British Columbia.

Léonard, A. (2010). The employment insurance program in Canada : how it works. Ottawa : Library of Parliament.

Longo, C. J., Fitch, M., Deber, R. B., \& Williams, A. P. (2006). Financial and family burden associated with cancer treatment in Ontario, Canada. Support Care Cancer, 14(11), 10771085. https://doi.org/10.1007/s00520-006-0088-8

Lu, L., O'Sullivan, E., \& Sharp, L. (2019). Cancer-related financial hardship among head and neck cancer survivors: Risk factors and associations with health-related quality of life. Psycho-oncology., 28(4), 863-871. https://doi.org/10.1002/pon.5034 


\section{FINANCIAL IMPACT OF CANCER IN YOUNG ADULTS}

Martinez, B. A. F., Leotti, V. B., Silva, G. d. S. E., Nunes, L. N., Machado, G., \& Corbellini, L. G. (2017). Odds Ratio or Prevalence Ratio? An Overview of Reported Statistical Methods and Appropriateness of Interpretations in Cross-sectional Studies with Dichotomous Outcomes in Veterinary Medicine. Frontiers in veterinary science, 4, 193. https://doi.org/10.3389/fvets.2017.00193

Mattews, M., Basky, G. (2001). Closer to home: The burden of out-of-pocket expenses on cancer patients in Newfoundland and Labrador. Memorial University of Newfoundland.

Mehnert, A. (2011). Employment and work-related issues in cancer survivors. Critical Reviews in Oncology and Hematology, 77(2), 109-130.

https://doi.org/10.1016/j.critrevonc.2010.01.004

Mitchell, A. J., Ferguson, D. W., Gill, J., Paul, J., \& Symonds, P. (2013). Depression and anxiety in long-term cancer survivors compared with spouses and healthy controls: a systematic review and meta-analysis. Lancet Oncology, 14(8), 721-732. https://doi.org/10.1016/S1470-2045(13)70244-4

Mols, F., Thong, M. S. Y., Vissers, P., Nijsten, T., \& van de Poll-Franse, L. V. (2012). Socioeconomic implications of cancer survivorship: Results from the PROFILES registry. European Journal of Cancer, 48(13), 2037-2042.

https://doi.org/10.1016/j.ejca.2011.11.030

Ó Céilleachair, A., Hanly, P., Skally, M., O'Leary, E., O'Neill, C., Fitzpatrick, P., Kapur, K., Staines, A., \& Sharp, L. (2017). Counting the cost of cancer: out-of-pocket payments made by colorectal cancer survivors. Supportive care in cancer : official journal of the Multinational Association of Supportive Care in Cancer, 25(9), 2733-2741.

https://doi.org/10.1007/s00520-017-3683-y 


\section{FINANCIAL IMPACT OF CANCER IN YOUNG ADULTS}

Oliveira, C., Bremner, K., Ni, A., Alibhai, S., Laporte, A., \& Krahn, M. (2014). Patient time and out-of-pocket costs for long-term prostate cancer survivors in Ontario, Canada. Research and Practice, 8(1), 9-20. https://doi.org/10.1007/s11764-013-0305-7

Palacios, M., Barua, B., \& Canadian Electronic Library, d. (2018). The Price of Public Health Care Insurance, 2018. Vancouver, BC, CA: Fraser Institute.

Papanicolas, I., Woskie, L., \& Jha, A. (2018). Health Care Spending in the United States and Other High-Income Countries. Jama-Journal Of The American Medical Association, 319(10), 1024-1039. https://doi.org/10.1001/jama.2018.1150

Park, J., \& Look, K. A. (2018). Relationship Between Objective Financial Burden and the Health-Related Quality of Life and Mental Health of Patients With Cancer. Journal of oncology practice, 14(2), e113. https://doi.org/10.1200/JOP.2017.027136

Parsons, H. M., Harlan, L. C., Lynch, C. F., Hamilton, A. S., Wu, X. C., Kato, I., Schwartz, S. M., Smith, A. W., Keel, G., \& Keegan, T. H. (2012). Impact of cancer on work and education among adolescent and young adult cancer survivors. J Clin Oncol, 30(19), 2393-2400. https://doi.org/10.1200/JCO.2011.39.6333

Pisu, M., Azuero, A., Benz, R., McNees, P., \& Meneses, K. (2017). Out-of-pocket costs and burden among rural breast cancer survivors. Cancer Medicine, 6(3), 572-581. https://doi.org/10.1002/cam4.1017

Prue, G., Rankin, J., Allen, J., Gracey, J., \& Cramp, F. (2006). Cancer-related fatigue: A critical appraisal. European Journal of Cancer, 42(7), 846-863.

https://doi.org/10.1016/j.ejca.2005.11.026 


\section{FINANCIAL IMPACT OF CANCER IN YOUNG ADULTS}

Pryce, J., Munir, F., \& Haslam, C. (2007). Cancer survivorship and work: Symptoms, supervisor response, co-worker disclosure and work adjustment. Journal of Occupational Rehabilitation, 17(1), 83-92. https://doi.org/10.1007/s10926-006-9040-5

Quinlan, E., Thomas-Maclean, R., Hack, T., Kwan, W., Miedema, B., Tatemichi, S., Towers, A., \& Tilley, A. (2009). The impact of breast cancer among Canadian women: disability and productivity. Work (Reading, Mass.), 34(3), 285-296. https://doi.org/10.3233/WOR$\underline{2009-0926}$

Quintini, G., \& Martin, S. (2006). Starting Well or Losing their Way?: The Position of Youth in the Labour Market in OECD Countries. IDEAS Working Paper Series from RePEc.

Rosenzweig, M., West, M., Matthews, J., Stokan, M., Yoojin Kook, Y. K., Gallups, S., \& Diergaarde, B. (2019). Financial Toxicity Among Women With Metastatic Breast Cancer. Oncology nursing forum, 46(1), 83-91. https://doi.org/10.1188/19.0NF.83-91

Salsman, J. M., Bingen, K., Barr, R.D., \& Freyer, D.R. (2019). Understanding, measuring, and addressing the financial impact of cancer on adolescents and young adults. Pediatric blood and cancer. https://doi.org/10.1002/pbc.27660

Šaltyte Benth, J., Dahl, F., Lurås, H., \& Dahl, A. (2014). A controlled study of income development for breast cancer survivors in Norway. Research and Practice, 8(2), 239247. https://doi.org/10.1007/s11764-013-0324-4

Schwartz, L., \& Drotar, D. (2006). Posttraumatic Stress and Related Impairment in Survivors of Childhood Cancer in Early Adulthood Compared to Healthy Peers. Journal of Pediatric Psychology, 31(4), 356-366. https://doi.org/10.1093/jpepsy/jsj018 


\section{FINANCIAL IMPACT OF CANCER IN YOUNG ADULTS}

Sharp, L., Carsin, A. E., \& Timmons, A. (2013). Associations between cancer-related financial stress and strain and psychological well-being among individuals living with cancer. Psycho-Oncology, 22(4), 745-755. https://doi.org/10.1002/pon.3055

Short, P. F., Vasey, J. J., \& Belue, R. (2008). Work disability associated with cancer survivorship and other chronic conditions. Psycho-Oncology, 17(1), 91-97. https://doi.org/10.1002/pon.1194

Soejima, T., \& Kamibeppu, K. (2016). Are cancer survivors well-performing workers? A systematic review. Asia-Pacific journal of clinical oncology., 12(4), e383-e397. https://doi.org/10.1111/ajco.12515

Soril, L. J. J., Adams, T., Phipps-Taylor, M., Winblad, U., \& Clement, F. (2017). Is Canadian Healthcare Affordable? A Comparative Analysis of the Canadian Healthcare System from 2004 to 2014. Healthcare policy = Politiques de sante, 13(1), 43-58. https://doi.org/10.12927/hcpol.2017.25192

Souza, J. A., Yap, B. J., Hlubocky, F. J., Wroblewski, K., Ratain, M. J., Cella, D., \& Daugherty, C. K. (2014). The development of a financial toxicity patient-reported outcome in cancer: The COST measure. Cancer, 120(20), 3245-3253. https://doi.org/10.1002/cncr.28814

Statistics Canada. (2011). Canada's rural population since 1851.

http://www12.statcan.gc.ca/census-recensement/2011/as-sa/98-310-x/98-310x2011003_2-eng.cfm

Statistics Canada. (2014a). Canadian Community Health Survey. https://www23.statcan.gc.ca/imdb/p3Instr.pl?Function=assembleInstr\&Item_Id=214314 


\section{FINANCIAL IMPACT OF CANCER IN YOUNG ADULTS}

Statistics Canada. (2014b). Canadian Financial Capability Survey.

https://www23.statcan.gc.ca/imdb/p3Instr.pl?Function=assembleInstr\&a=1\&\&lang=en\& Item_Id=201522

Statistics Canada. (2016). Canadian Income Survey. http://www150.statcan.gc.ca/n1/dailyquotidien/180313/dq180313a-eng.htmSu, T. T., Azzani, M., Tan, F. L., \& Loh, S. Y. (2018). Breast cancer survivors: return to work and wage loss in selected hospitals in Malaysia. Supportive Care in Cancer, 26(5), 1617-1624. https://doi.org/10.1007/s00520$\underline{017-3987-y}$

Tamhane, A. R., Westfall, A. O., Burkholder, G. A., \& Cutter, G. R. (2017). Prevalence odds ratio versus prevalence ratio: choice comes with consequences. Statistics in Medicine, 36(23), 3760-3760. https://doi.org/10.1002/sim.7375

Tamminga, S. J., de Boer, A. G. E. M., Verbeek, J. H. A. M., \& Frings-Dresen, M. H. W. (2010). Return-to-work interventions integrated into cancer care: a systematic review. Occupational and Environmental Medicine, 67(9), 639. https://doi.org/10.1136/oem.2009.050070

Teckle, P., Peacock, S., McBride, M. L., Bentley, C., Goddard, K., \& Rogers, P. (2018). Longterm effects of cancer on earnings of childhood, adolescent and young adult cancer survivors - a population- based study from British Columbia, Canada. BMC Health Services Research, 18(1). https://doi.org/10.1186/s12913-018-3617-5

Turner \& Associates. (2008). Issues of Access to Cancer Drugs in Canada: A Report for the Canadian Cancer Action Network. http://www.ccanceraction.ca/wpcontent/uploads/2014/11/3-CCAN-Pharma-Report-Final-PDF.pdf 


\section{FINANCIAL IMPACT OF CANCER IN YOUNG ADULTS}

van Den Beuken-van Everdingen, M. H. J., Hochstenbach, L. M. J., Joosten, E. A. J., TjanHeijnen, V. C. G., \& Janssen, D. J. A. (2016). Update on Prevalence of Pain in Patients With Cancer: Systematic Review and Meta-Analysis. Journal of Pain and Symptom Management, 51(6), 1070-1090.e1079. https://doi.org/10.1016/j.jpainsymman.2015.12.340

Von Ah, A. D., Storey, A. S., Crouch, A. A., Johns, A. S., Dodson, A. J., \& Dutkevitch, A. S. (2017). Relationship of Self-reported Attentional Fatigue to Perceived Work Ability in Breast Cancer Survivors. Cancer Nursing, 40(6), 464-470. https://doi.org/10.1097/NCC.0000000000000444

Webley, P., Burgoyne,C., Lea, S., \& Young,B. (2001). The economic psychology of everyday life. Hove: Psychology Press. http://doi.org/10.4324/9780203138038

Whitney, R., Bell, J., Reed, S., Lash, R., Bold, R., Kim, K., Davis, A., Copenhaver, D., \& Joseph, J. (2016). Predictors of financial difficulties and work modifications among cancer survivors in the United States. Research and Practice, 10(2), 241-250. https://doi.org/10.1007/s11764-015-0470-y

Wiczer, D. (2017). Earnings Losses Through Unemployment and Unemployment Duration. Economic Synopses, 2017(13). https://doi.org/10.20955/es.2017.13

Wong, S. T., \& Regan, S. (2009). Patient perspectives on primary health care in rural communities: effects of geography on access, continuity and efficiency. Rural and remote health, 9(1), 1142-1142. https://doi.org/10.14288/1.0084588

Xiao, J. J., Chatterjee, S., \& Kim, J. (2014). Factors associated with financial independence of young adults. International Journal of Consumer Studies, 38(4), 394-403.

https://doi.org/10.1111/ijcs.12106 
Yabroff, K. R., Dowling, E. C., Guy, G. P., Jr., Banegas, M. P., Davidoff, A., Han, X., Virgo, K. S., McNeel, T. S., Chawla, N., Blanch-Hartigan, D., Kent, E. E., Li, C., Rodriguez, J. L., de Moor, J. S., Zheng, Z., Jemal, A., \& Ekwueme, D. U. (2016). Financial Hardship Associated With Cancer in the United States: Findings From a Population-Based Sample of Adult Cancer Survivors. J Clin Oncol, 34(3), 259-267.

https://doi.org/10.1200/JCO.2015.62.0468

Zafar, S. Y., Peppercorn, J. M., Schrag, D., Taylor, D. H., Goetzinger, A. M., Zhong, X., \& Abernethy, A. P. (2013). The Financial Toxicity of Cancer Treatment: A Pilot Study Assessing Out-of-Pocket Expenses and the Insured Cancer Patient's Experience. Oncologist, 18(4), 381-390. https://doi.org/10.1634/theoncologist.2012-0279

Zajacova, A., Dowd, J. B., Schoeni, R. F., \& Wallace, R. B. (2015). Employment and income losses among cancer survivors: Estimates from a national longitudinal survey of American families. Cancer, 121(24), 4425-4432. https://doi.org/10.1002/cncr.29510 
FINANCIAL IMPACT OF CANCER IN YOUNG ADULTS

Table 1. Summary of Comparisons

\begin{tabular}{|c|c|c|c|c|c|c|c|}
\hline \multicolumn{8}{|c|}{ Age at Survey Completion } \\
\hline \multicolumn{4}{|c|}{$\leq 34$ years } & \multicolumn{4}{|c|}{$>34$ years } \\
\hline \multicolumn{2}{|c|}{$\frac{\text { Personal \& Household }}{\text { Income }}$} & \multicolumn{2}{|c|}{$\underline{\text { Assets \& Debts }}$} & \multicolumn{2}{|c|}{$\frac{\text { Personal \& Household }}{\text { Income }}$} & \multicolumn{2}{|c|}{$\underline{\text { Assets \& Debts }}$} \\
\hline Cancer & Control & Cancer & Control & Cancer & Control & Cancer & Control \\
\hline YACPRIME & $\mathrm{CCHS}$ & YACPRIME & CFCS & YACPRIME & CCHS & YACPRIME & CFCS \\
\hline$n=296$ & $n=296$ & $n=296$ & $n=290$ & $n=279$ & $n=279$ & $n=279$ & $n=268$ \\
\hline \multicolumn{2}{|c|}{ (Comparison 1) } & \multicolumn{2}{|c|}{ (Comparison 2) } & \multicolumn{2}{|c|}{ (Comparison 3) } & \multicolumn{2}{|c|}{ (Comparison 4) } \\
\hline \multicolumn{8}{|c|}{ Time Since Diagnosis } \\
\hline \multicolumn{4}{|c|}{$<5$ years } & \multicolumn{4}{|c|}{$\geq 5$ years } \\
\hline \multicolumn{2}{|c|}{$\frac{\text { Personal \& Household }}{\underline{\text { Income }}}$} & \multicolumn{2}{|c|}{$\underline{\text { Assets \& Debts }}$} & \multicolumn{2}{|c|}{$\frac{\text { Personal \& Household }}{\underline{\text { Income }}}$} & \multicolumn{2}{|c|}{$\underline{\text { Assets \& Debts }}$} \\
\hline Cancer & Control & Cancer & Control & Cancer & Control & Cancer & Control \\
\hline YACPRIME & $\mathrm{CCHS}$ & YACPRIME & CFCS & YACPRIME & $\mathrm{CCHS}$ & YACPRIME & CFCS \\
\hline$n=344$ & $n=344$ & $n=344$ & $n=343$ & $n=228$ & $n=228$ & $n=228$ & $n=228$ \\
\hline (Compar & on 5) & (Compar & on 6) & (Compar & on 7) & (Compar & on 8$)$ \\
\hline
\end{tabular}


Table 2. Summary Statistics for YACPRIME, CCHS and CFCS Comparison Samples

\begin{tabular}{|c|c|c|c|}
\hline & $\begin{array}{c}\text { YACPRIME } \\
N=\mathbf{5 7 5} \\
\text { Frequency }(\%)\end{array}$ & $\begin{array}{c}\text { CCHS } \\
N=575 \\
\text { Frequency }(\%)\end{array}$ & $\begin{array}{c}\text { CFCS } \\
N=558 \\
\text { Frequency }(\%)\end{array}$ \\
\hline \multicolumn{4}{|l|}{ Age } \\
\hline $18-24$ & $33(5.7)$ & $33(5.7)$ & $27(4.8)$ \\
\hline $25-34$ & $263(45.7)$ & $263(45.7)$ & $263(47.1)$ \\
\hline $35-44$ & $259(45.0)$ & $259(45.0)$ & $248(44.4)$ \\
\hline $45-54$ & $16(2.8)$ & $16(2.8)$ & $16(2.9)$ \\
\hline $55-64$ & $4(0.7)$ & $4(0.7)$ & $4(0.7)$ \\
\hline \multicolumn{4}{|l|}{ Sex } \\
\hline Male & $76(13.2)$ & $76(13.2)$ & $76(13.6)$ \\
\hline Female & $499(86.8)$ & $499(86.8)$ & $482(86.4)$ \\
\hline \multicolumn{4}{|l|}{ Language } \\
\hline English & $529(92.0)$ & Not & Not \\
\hline French & $46(8.0)$ & Available & Available \\
\hline \multicolumn{4}{|l|}{ Province/Territory } \\
\hline Atlantic & $109(19.0)$ & $55(9.6)$ & $139(24.9)$ \\
\hline Quebec & $61(10.6)$ & $112(19.5)$ & $81(14.5)$ \\
\hline Ontario & $181(31.5)$ & $177(30.8)$ & $110(19.7)$ \\
\hline Manitoba, Saskatchewan and Alberta & $142(24.7)$ & $134(23.3)$ & $179(32.1)$ \\
\hline British Columbia & $79(13.7)$ & $63(11.0)$ & $49(8.8)$ \\
\hline Yukon and Northwest Territories & $3(0.5)$ & $34(5.9)$ & N/A \\
\hline \multicolumn{4}{|l|}{ Race } \\
\hline White & $509(88.5)$ & \multirow{5}{*}{$\begin{array}{c}\text { Not } \\
\text { Available }\end{array}$} & \multirow{5}{*}{$\begin{array}{c}\text { Not } \\
\text { Available }\end{array}$} \\
\hline Asian & $18(3.1)$ & & \\
\hline Aboriginal/First Nations & $13(2.3)$ & & \\
\hline Multi-racial/Ethnic Identity & $21(3.7)$ & & \\
\hline Other & $14(2.4)$ & & \\
\hline \multicolumn{4}{|l|}{ Relationship Status } \\
\hline Single & $180(31.3)$ & $235(40.9)$ & $187(33.8)$ \\
\hline In a relationship & $395(68.7)$ & $340(59.2)$ & $366(66.1)$ \\
\hline \multicolumn{4}{|l|}{ Children } \\
\hline No children & $344(59.8)$ & Not & Not \\
\hline Children & $231(40.2)$ & Available & Available \\
\hline \multicolumn{4}{|l|}{ Education } \\
\hline$\leq 12$ years & $27(4.7)$ & - & $27(4.8)$ \\
\hline $13-14$ years & $88(15.3)$ & - & $88(15.8)$ \\
\hline$\geq 15$ years & $460(80.0)$ & - & $443(79.5)$ \\
\hline$<$ Secondary grad & - & $27(4.7)$ & - \\
\hline Secondary grad & - & $31(5.4)$ & - \\
\hline Some post-secondary & - & $204(35.5)$ & - \\
\hline Post-secondary grad & - & $313(54.4)$ & - \\
\hline
\end{tabular}


Table 3. YACPRIME Sample $(N=575)$ Employment and Demographic Variables

\section{Current Employment Status}

Other

Frequency

(\%)

On disability

On leave

$49(8.5)$

Full time worker, student or homemaker

$34(5.9)$

Unemployed

$308(53.5)$

Part time worker or student

$82(14.3)$

$94(16.3)$

Change in Employment Status $(n=463)$

It has not changed because of cancer or its treatment

$55(11.9)$

Quit working completely

$138(29.8)$

Quit going to school completely

$26(5.6)$

Full-time employee to part-time employee

$18(3.9)$

Full-time student to part-time student

$11(2.4)$

Took more than 2 weeks total time off from work

$181(39.1)$

Took more than 2 weeks total time off from school

$34(7.3)$

Cancer Duration $(n=572)$

0 to less than 5 years

$344(60.1)$

5 or more years

$228(39.9)$

\section{Cancer Diagnosis}

Breast

Female Genitourinary

$57(9.9)$

Male Genitourinary

9 (1.6)

Thyroid

$44(7.7)$

Blood

$156(27.1)$

Head and neck

$44(7.7)$

Gastrointestinal

$54(9.4)$

Skin

$17(3.0)$

Multiple types

$7(1.2)$

Other types

$29(5.0)$

\section{Cancer Stage}

Stage 1

79 (13.7)

Stage 2

$161(28.0)$

Stage 3

$132(23.0)$

Stage 4

$79(13.7)$

$78(13.6)$

Don't know

$46(8.0)$

Not applicable

$63(12.2)$

Less than 30 days

30 days to less than 6 months

$109(21.1)$

6 months to less than 1 year

177 (34.2) 
FINANCIAL IMPACT OF CANCER IN YOUNG ADULTS

3 years or more

Out-of-pocket cancer expenses per month

Less than $\$ 100$

$\$ 100-\$ 250$

$\$ 250-\$ 500$

$\$ 500-\$ 1000$

$\$ 1000$ or more
$74(14.3)$

$232(40.3)$

$169(29.4)$

$97(16.9)$

$40(7.0)$

$37(6.4)$ 


\section{FINANCIAL IMPACT OF CANCER IN YOUNG ADULTS}

Table 4. Financial Impact of Cancer on YAs compared to Age, Sex and Education Matched Controls Based on Current Age

\begin{tabular}{|c|c|c|c|c|c|c|c|c|c|c|}
\hline & \multicolumn{5}{|c|}{ YAs 34 and younger } & \multicolumn{5}{|c|}{ YAs 35 and older } \\
\hline & $\begin{array}{c}\text { YA Cancer } \\
\text { Survivors } \\
n=296 \\
n(\text { valid \%) }\end{array}$ & $\begin{array}{c}\text { YAs w/o } \\
\text { Cancer } \\
n=296 \\
n(\text { valid \%) }\end{array}$ & $\chi^{2}$ & & $P$ value & $\begin{array}{c}\text { YA Cancer } \\
\text { Survivors } \\
n=279 \\
n(\text { valid \%) }\end{array}$ & $\begin{array}{c}\text { YAs w/o } \\
\text { Cancer } \\
n=279 \\
n(\text { valid \%) }\end{array}$ & $\chi^{2}$ & & $P$ value \\
\hline Personal Income in 2014 & & & 4.000 & & .406 & & & 4.423 & & .352 \\
\hline None or $<\$ 20,000$ & $114(38.5)$ & $97(35.9)$ & & & & $68(24.4)$ & $56(21.9)$ & & & \\
\hline$\$ 20,000$ to $<\$ 40,000$ & $75(25.3)$ & $79(29.3)$ & & & & $57(20.4)$ & $69(27.0)$ & & & \\
\hline$\$ 40,000$ to $<\$ 60,000$ & $50(16.9)$ & $52(19.3)$ & & & & $66(23.7)$ & $65(25.4)$ & & & \\
\hline$\$ 60,000$ to $<\$ 80,000$ & $27(9.1)$ & $25(9.3)$ & & & & $37(13.3)$ & $30(11.7)$ & & & \\
\hline$\$ 80,000$ or more & $30(10.1)$ & $17(6.3)$ & & & & $50(18.0)$ & $36(14.1)$ & & & \\
\hline Total Household Income & & & 2.708 & & .608 & & & 3.108 & & .540 \\
\hline None or $<\$ 20,000$ & $37(12.8)$ & $37(12.6)$ & & & & $23(8.6)$ & $24(8.6)$ & & & \\
\hline$\$ 20,000$ to $<\$ 40,000$ & $46(16.0)$ & $60(20.4)$ & & & & $26(9.7)$ & $37(13.3)$ & & & \\
\hline$\$ 40,000$ to $<\$ 60,000$ & $42(14.6)$ & $41(13.9)$ & & & & $39(14.5)$ & $46(16.5)$ & & & \\
\hline$\$ 60,000$ to $<\$ 80,000$ & $41(14.2)$ & $46(15.6)$ & & & & $40(14.9)$ & $43(15.5)$ & & & \\
\hline$\$ 80,000$ or more & $122(42.4)$ & $110(37.4)$ & & & & $141(52.4)$ & $128(46.0)$ & & & \\
\hline & $\begin{array}{c}\text { YA Cancer } \\
\text { Survivors } \\
n=296 \\
n(\text { valid \%) }\end{array}$ & $\begin{array}{c}\text { YAs w/o } \\
\text { Cancer } \\
n=290 \\
n(\text { valid \%) }\end{array}$ & $\chi^{2}$ & $\begin{array}{c}P \\
\text { value }\end{array}$ & PR $[95 \% \mathrm{CI}]$ & $\begin{array}{c}\text { YA Cancer } \\
\text { Survivors } \\
n=279 \\
n(\text { valid \%) }\end{array}$ & $\begin{array}{c}\text { YAs w/o } \\
\text { Cancer } \\
n=268 \\
n(\text { valid \%) }\end{array}$ & $\chi^{2}$ & $\begin{array}{c}P \\
\text { value }\end{array}$ & PR [95\% CI] \\
\hline $\begin{array}{l}\text { Do you have any of the } \\
\text { following types of } \\
\text { debts?* }\end{array}$ & & & & & & & & & & \\
\hline Mortgages & $125(43.0)$ & $152(53.5)$ & 6.427 & .011 & $1.23[1.05,1.44]$ & $170(62.5)$ & $169(66.3)$ & 0.817 & .366 & $1.11[0.88,1.40]$ \\
\hline Student loans & $126(43.3)$ & $106(37.3)$ & 2.132 & .144 & $1.16[0.95,1.42]$ & $60(22.1)$ & $30(11.8)$ & 9.849 & .002 & $1.88[1.25,2.81]$ \\
\hline Payday loans & $11(3.8)$ & $2(0.7)$ & 6.154 & .013 & $5.37[1.20,24.0]$ & $7(2.6)$ & $2(0.8)$ & 2.510 & .113 & $3.28[0.69,15.6]$ \\
\hline Other loans & $75(25.8)$ & $86(30.3)$ & 1.449 & .229 & $1.06[0.96,1.18]$ & $74(27.2)$ & $95(37.3)$ & 6.101 & .014 & $1.16[1.03,1.31]$ \\
\hline $\begin{array}{l}\text { Outstanding credit card } \\
\text { balance }\end{array}$ & $142(48.8)$ & $101(35.6)$ & 10.316 & .001 & $1.37[1.13,1.67]$ & $152(55.9)$ & $107(42.0)$ & 10.206 & .001 & $1.33[1.11,1.59]$ \\
\hline $\begin{array}{l}\text { Outstanding line of credit } \\
\text { balance }\end{array}$ & $99(34.0)$ & $68(23.9)$ & 7.082 & .008 & $1.42[1.09,1.85]$ & $134(49.3)$ & $99(38.8)$ & 5.817 & .016 & $1.27[1.04,1.54]$ \\
\hline None & $42(14.4)$ & $37(13.0)$ & 0.239 & .625 & $1.11[0.73,1.67]$ & $24(8.8)$ & $34(13.3)$ & 2.733 & .098 & $1.05[0.99,1.12]$ \\
\hline Other & $24(8.2)$ & $0(0.0)$ & 24.443 & $<.001$ & N/A & $23(8.5)$ & $0(0.0)$ & 22.547 & $<.001$ & N/A \\
\hline $\begin{array}{l}\text { Total value of these } \\
\text { debts/liabilities }\end{array}$ & & & 24.554 & $<.001$ & & & & 3.691 & .595 & \\
\hline Less than $\$ 50,000$ & $139(57.0)$ & $92(42.2)$ & & & & $89(40.6)$ & $72(37.3)$ & & & \\
\hline$\$ 50,000$ to $\$ 99,999$ & $23(9.4)$ & $22(10.1)$ & & & & $23(10.5)$ & $22(11.4)$ & & & \\
\hline
\end{tabular}




\section{FINANCIAL IMPACT OF CANCER IN YOUNG ADULTS}

Table 4 (Continued). Financial Impact of Cancer on YAs compared to Age, Sex and Education Matched Controls Based on Current Age

\begin{tabular}{|c|c|c|c|c|c|c|c|c|c|c|}
\hline$\$ 100,000$ to $\$ 149,999$ & $2(0.8)$ & $2(9.2)$ & & & & $16(7.3)$ & $24(12.4)$ & & & \\
\hline$\$ 150,000$ to $\$ 199,999$ & $10(4.1)$ & $15(6.9)$ & & & & $17(7.8)$ & $16(8.3)$ & & & \\
\hline$\$ 200,000$ to $\$ 249,999$ & $20(8.2)$ & $24(11.0)$ & & & & $16(7.3)$ & $11(5.7)$ & & & \\
\hline$\$ 250,000$ or more & $50(20.5)$ & 45 (20.6) & & & & $58(26.5)$ & $48(24.9)$ & & & \\
\hline \multicolumn{11}{|l|}{$\begin{array}{l}\text { Do you own any of the } \\
\text { following types of } \\
\text { assets?* }\end{array}$} \\
\hline House or property & $117(41.1)$ & $166(58.5)$ & 17.224 & $<.001$ & $1.42[1.20,1.68]$ & $177(65.1)$ & $203(79.3)$ & 13.225 & $<.001$ & $1.69[1.26,2.25]$ \\
\hline Vehicles & $203(71.2)$ & $250(88.0)$ & 24.737 & $<.001$ & $2.40[1.67,3.46]$ & $225(82.7)$ & $233(91.0)$ & 7.891 & .005 & $1.92[1.20,3.07]$ \\
\hline None & 67 (23.6) & $27(9.5)$ & 20.397 & $<.001$ & $2.48[1.64,3.76]$ & $28(10.3)$ & $15(5.9)$ & 3.467 & .063 & $1.76[0.96,3.21]$ \\
\hline Other & $5(1.8)$ & $1(0.4)$ & 2.695 & .101 & $5.00[0.59,42.5]$ & $6(2.2)$ & $1(0.4)$ & 3.322 & .068 & $5.65[0.68,46.6]$ \\
\hline Value of Assets & & & 16.529 & .002 & & & & 31.460 & $<.001$ & \\
\hline Less than $\$ 100,000$ & $155(63.8)$ & $85(47.0)$ & & & & $91(43.1)$ & $27(17.2)$ & & & \\
\hline$\$ 100,000$ to $<\$ 200,000$ & $5(2.1)$ & $10(5.5)$ & & & & $8(3.8)$ & $14(8.9)$ & & & \\
\hline$\$ 200,000$ to $<\$ 300,000$ & $13(5.3)$ & $22(12.2)$ & & & & $21(10.0)$ & $15(9.6)$ & & & \\
\hline$\$ 300,000$ to $<\$ 500,000$ & $37(15.2)$ & $38(21.0)$ & & & & $42(19.9)$ & $40(25.5)$ & & & \\
\hline \multicolumn{11}{|c|}{$\begin{aligned} \text { NOTE: } & \mathrm{PR}=\text { Prevalence Ratio } \\
& \mathrm{CI}=\text { Confidence Interval } \\
& \mathrm{w} / \mathrm{o}=\text { without } \\
& \text { *Responses can include } \mathrm{r} \\
& \text { Bold tvpeface indicates } \mathrm{s}\end{aligned}$} \\
\hline
\end{tabular}




\section{FINANCIAL IMPACT OF CANCER IN YOUNG ADULTS}

Table 5. Financial Impact of Cancer on YAs compared to Age, Sex and Education Matched Controls Based on Time Since Diagnosis

\begin{tabular}{|c|c|c|c|c|c|c|c|c|c|c|}
\hline & \multicolumn{5}{|c|}{ Diagnosed less than 5 years } & \multicolumn{5}{|c|}{ Diagnosed 5 or more years } \\
\hline & $\begin{array}{c}\text { YA Cancer } \\
\text { Survivors } \\
n=344 \\
n(\text { valid \%) }\end{array}$ & $\begin{array}{c}\text { YAs w/o } \\
\text { Cancer } \\
n=344 \\
n(\text { valid \%) }\end{array}$ & $\chi^{2}$ & & $P$ value & $\begin{array}{c}\text { YA Cancer } \\
\text { Survivors } \\
n=228 \\
n(\text { valid \%) }\end{array}$ & $\begin{array}{c}\text { YAs w/o } \\
\text { Cancer } \\
n=228 \\
n(\text { valid \%) }\end{array}$ & $\chi^{2}$ & & $P$ value \\
\hline $\begin{array}{l}\text { Personal Income in } \\
2014\end{array}$ & & & 10.127 & & .038 & & & 1.504 & & .826 \\
\hline None or $<\$ 20,000$ & $120(34.9)$ & $89(29.2)$ & & & & $62(27.3)$ & $58(28.4)$ & & & \\
\hline$\$ 20,000$ to $<\$ 40,000$ & $72(20.9)$ & $88(28.9)$ & & & & $58(25.6)$ & $57(27.9)$ & & & \\
\hline$\$ 40,000$ to $<\$ 60,000$ & $66(19.2)$ & $64(21.0)$ & & & & $49(21.6)$ & $46(22.5)$ & & & \\
\hline$\$ 80,000$ or more & $50(14.5)$ & $28(9.2)$ & & & & $30(13.2)$ & $20(9.8)$ & & & \\
\hline Total Household & & & 9.032 & & .060 & & & 4.197 & & .380 \\
\hline \multicolumn{11}{|l|}{ Income } \\
\hline None or $<\$ 20,000$ & $44(13.1)$ & $28(8.1)$ & & & & $16(7.3)$ & $17(7.5)$ & & & \\
\hline$\$ 20,000$ to $<\$ 40,000$ & $42(12.5)$ & $63(18.3)$ & & & & $29(13.2)$ & $37(16.2)$ & & & \\
\hline$\$ 40,000$ to $<\$ 60,000$ & $54(16.1)$ & $52(15.1)$ & & & & $27(12.3)$ & $40(17.5)$ & & & \\
\hline$\$ 60,000$ to $<\$ 80,000$ & $42(12.5)$ & $53(15.4)$ & & & & $38(17.3)$ & $32(14.0)$ & & & \\
\hline \multirow[t]{2}{*}{$\$ 80,000$ or more } & $153(45.7)$ & $148(43.0)$ & & & & $110(50.0)$ & $102(44.7)$ & & & \\
\hline & $\begin{array}{c}\text { YA Cancer } \\
\text { Survivors } \\
n=344 \\
n(\text { valid \%) }\end{array}$ & $\begin{array}{c}\text { YAs w/o } \\
\text { Cancer } \\
n=343 \\
n(\text { valid \%) }\end{array}$ & $\chi^{2}$ & $\begin{array}{c}P \\
\text { value }\end{array}$ & PR $[95 \% \mathrm{CI}]$ & $\begin{array}{c}\text { YA Cancer } \\
\text { Survivors } \\
n=228 \\
n(\text { valid } \%)\end{array}$ & $\begin{array}{c}\text { YAs w/o } \\
\text { Cancer } \\
n=228 \\
n(\text { valid \%) }\end{array}$ & $\chi^{2}$ & $\begin{array}{c}P \\
\text { value }\end{array}$ & PR $[95 \% \mathrm{CI}]$ \\
\hline \multicolumn{11}{|l|}{$\begin{array}{l}\text { Do you have any of } \\
\text { the following types of } \\
\text { debts?* }\end{array}$} \\
\hline Mortgages & $179(53.1)$ & $189(57.4)$ & 1.263 & .261 & $1.10[0.93,1.31]$ & $114(50.9)$ & $132(60.8)$ & 4.412 & .036 & $1.25[1.01,1.55]$ \\
\hline Student loans & $125(37.1)$ & $101(30.7)$ & 3.035 & .081 & $1.21[0.98,1.50]$ & $60(26.8)$ & $41(18.9)$ & 3.888 & .049 & $1.42[1.00,2.01]$ \\
\hline Payday loans & $12(3.6)$ & $3(0.9)$ & 5.306 & .021 & $3.91[1.11,13.7]$ & $6(2.7)$ & $4(1.8)$ & 0.347 & .556 & $1.45[0.42,5.08]$ \\
\hline Other loans & $86(25.5)$ & $115(35.0)$ & 7.033 & .008 & $1.15[1.04,1.27]$ & $62(27.7)$ & $68(31.3)$ & 0.709 & .400 & $1.05[0.93,1.19]$ \\
\hline $\begin{array}{l}\text { Outstanding credit card } \\
\text { balance }\end{array}$ & $169(50.1)$ & $136(41.3)$ & 5.206 & .023 & $1.21[1.03,1.43]$ & $123(54.9)$ & 80 (36.9) & 14.446 & $<.001$ & $1.49[1.21,1.84]$ \\
\hline $\begin{array}{l}\text { Outstanding line of } \\
\text { credit balance }\end{array}$ & $136(40.4)$ & $108(32.8)$ & 4.065 & .044 & $1.23[1.00,1.50]$ & $97(43.3)$ & $72(33.2)$ & 4.779 & .029 & $1.31[1.03,1.66]$ \\
\hline None & $38(11.3)$ & $41(12.5)$ & 0.224 & .636 & $1.01[0.96,1.07]$ & $28(12.5)$ & $31(14.3)$ & 0.303 & .582 & $1.02[0.95,1.10]$ \\
\hline Other & $32(9.5)$ & $0(0.0)$ & 32.817 & $<.001$ & N/A & $14(6.3)$ & $0(0.0)$ & 14.007 & $<.001$ & N/A \\
\hline $\begin{array}{l}\text { Total value of these } \\
\text { debts/liabilities }\end{array}$ & & & 16.665 & .005 & & & & 17.697 & .003 & \\
\hline
\end{tabular}




\section{FINANCIAL IMPACT OF CANCER IN YOUNG ADULTS}

Table 5 (Continued). Financial Impact of Cancer on YAs compared to Age, Sex, and Education Matched Controls Based on Time Since Diagnosis

\begin{tabular}{|c|c|c|c|c|c|c|c|c|c|c|}
\hline Less than $\$ 50,000$ & $138(47.8)$ & $102(39.8)$ & & & & $90(52.3)$ & $61(37.0)$ & & & \\
\hline$\$ 50,000$ to $\$ 99,999$ & $24(8.3)$ & $31(12.1)$ & & & & $22(12.8)$ & $19(11.5)$ & & & \\
\hline$\$ 100,000$ to $\$ 149,999$ & $10(3.5)$ & $25(9.8)$ & & & & $7(4.1)$ & $22(13.3)$ & & & \\
\hline$\$ 150,000$ to $\$ 199,999$ & $16(5.5)$ & $24(9.4)$ & & & & $11(6.4)$ & $16(9.7)$ & & & \\
\hline$\$ 250,000$ or more & $80(27.7)$ & $57(22.3)$ & & & & $27(15.7)$ & $38(23.0)$ & & & \\
\hline \multicolumn{11}{|l|}{$\begin{array}{l}\text { Do you own any of the } \\
\text { following types of } \\
\text { assets?* }\end{array}$} \\
\hline House or property & $169(50.6)$ & $213(64.4)$ & 12.860 & $<.001$ & $1.39[1.16,1.66]$ & $122(55.5)$ & $149(68.3)$ & 7.717 & .005 & $1.41[1.10,1.80]$ \\
\hline Vehicles & $251(75.1)$ & $293(88.5)$ & 19.965 & $<.001$ & $2.17[1.52,3.08]$ & $175(79.5)$ & $195(89.4)$ & 8.190 & .004 & $1.94[1.22,3.09]$ \\
\hline $\begin{array}{l}\text { Collections, antiques, } \\
\text { jewels and other valuables }\end{array}$ & $58(17.4)$ & $85(25.7)$ & 6.706 & .010 & $1.11[1.03,1.20]$ & $51(23.2)$ & $56(25.7)$ & 0.373 & .542 & $1.03[0.93,1.15]$ \\
\hline None & $61(18.3)$ & $27(8.2)$ & 14.908 & $<.001$ & $2.25[1.47,3.44]$ & $34(15.5)$ & $15(6.9)$ & 8.101 & .004 & $2.25[1.26,4.00]$ \\
\hline Other & $7(2.1)$ & $1(0.3)$ & 4.518 & .034 & $6.96[0.86,56.2]$ & $4(1.8)$ & $0(0.0)$ & 4.000 & .045 & $\mathrm{~N} / \mathrm{A}$ \\
\hline Less than $\$ 100,000$ & $158(55.8)$ & 78 (37.9) & & & & $88(52.1)$ & $42(32.1)$ & & \multirow{5}{*}{.001} & \\
\hline$\$ 100,000$ to $<\$ 200,000$ & $8(2.8)$ & $20(9.7)$ & & & & $4(2.4)$ & $11(8.4)$ & & & \\
\hline$\$ 200,000$ to $<\$ 300,000$ & $14(4.9)$ & $22(10.7)$ & & & & $19(11.2)$ & $11(8.4)$ & & & \\
\hline$\$ 300,000$ to $<\$ 500,000$ & 47 (16.6) & $43(20.9)$ & & & & $32(18.9)$ & $32(24.4)$ & & & \\
\hline$\$ 500,000$ or more & $56(19.8)$ & $43(20.9)$ & & & & $26(15.4)$ & $35(26.7)$ & & & \\
\hline $\begin{aligned} & \text { NOTE: } \text { PR }=\text { Prevalence Rat } \\
& \mathrm{CI}=\text { Confidence Inte } \\
& \text { w/o }=\text { without } \\
& \text { * Responses can incl } \\
& \text { Bold typeface indica }\end{aligned}$ & $\begin{array}{l}\text { more than } \\
\text { tatistically }\end{array}$ & $\begin{array}{l}\text { ategory an } \\
\text { ificant com }\end{array}$ & $\begin{array}{l}\text { y not a } \\
\text { sons }\end{array}$ & ap to & 343 or 228 & & & & & \\
\hline
\end{tabular}




\section{Appendix A: Financial Questions}

1. How much money do you estimate you currently spend out of pocket on cancer-related expenses?*

- Less than $\$ 100$

- $\$ 100-\$ 250$

- $\$ 250-\$ 500$

- $\$ 500-\$ 1,000$

- $\$ 1,000$ or more

2. Could you tell me which of the following categories best describes your personal income in 2016 ?

- None or $<\$ 20,000$

- $\$ 20,000$ to less than $\$ 40,000$

- $\$ 40,000$ to less than $\$ 60,000$

- $\$ 60,000$ to less than $\$ 80,000$

- $\$ 80,000$ or more

3. Which of the following categories best describes your total household income in 2016 ?

- None or $<\$ 20,000$

- $\$ 20,000$ to less than $\$ 40,000$

- $\$ 40,000$ to less than $\$ 60,000$

- $\$ 60,000$ to less than $\$ 80,000$

- $\$ 80,000$ or more

4. Do you or does anyone in your family currently have any of the following types of debts and liabilities?

- Mortgages

- Student loans

- Payday loans

- Other loans

- Outstanding credit card balance

- Outstanding line of credit balance

- None

- Other

5. In your estimation, what is the total of the debts and liabilities?

- Less than $\$ 50,000$

- $\$ 50,000$ to $\$ 99,999$

- $\$ 100,000$ to $\$ 149,999$

- $\$ 150,000$ to $\$ 199,999$

- $\$ 200,000$ to $\$ 249,999$

- $\$ 250,000$ or more 
FINANCIAL IMPACT OF CANCER IN YOUNG ADULTS

6. Do you or does anyone in your family own any of the following tangible assets?

- House or property

- Vehicles

- Collections, antiques, jewels and other valuables

- None

- Other

7. How much do you think these assets could be sold for today?

- Less than $\$ 100,000$

- $\$ 100,000$ to less than $\$ 200,000$

- $\$ 200,000$ to less than $\$ 300,000$

- $\$ 300,000$ to less than $\$ 500,000$

- $\$ 500,000$ or more

8. How much work have you missed because of your cancer diagnosis and/or treatment?*

- Less than 30 days

- 30 days to less than 6 months

- 6 months to less than 1 year

- 1 year to less than 3 years

- 3 years or more

9. Do you have insurance that covers all or part of your prescription medications?

- Yes

- No

10. Is your insurance a government sponsored plan, an employer sponsored benefit plan, or a plan sponsored through an association such as a union, trade association, or student organization?

- A government-sponsored plan

- An employer-sponsored benefit plan

- A plan sponsored through an association such as a union, trade association or student organization

- Other

NOTE: *Questions were only asked for the YACPRIME sample 
FINANCIAL IMPACT OF CANCER IN YOUNG ADULTS

Appendix B: Ethics Approval

Interdisciplinary Committee on

Ethics in Human Research (ICEHR)

\begin{tabular}{|l|l|}
\hline ICEHR Approval \#: & 20191990-SC \\
\hline $\begin{array}{l}\text { Researcher Portal } \\
\text { File \#: }\end{array}$ & 20191990 \\
\hline Project Title: & $\begin{array}{l}\text { The Cost of Young Adult Cancer: The Financial Impact of a } \\
\text { Cancer Diagnosis }\end{array}$ \\
\hline Associated Funding: & 20180017 \\
\hline Supervisor: & Dr. Sheila Garland \\
\hline $\begin{array}{l}\text { Clearance expiry } \\
\text { date: }\end{array}$ & October $\mathbf{3 1 , 2 0 2 0}$ \\
\hline
\end{tabular}

Dear Ms. Kaitlyn Mahon:

Thank you for your response to our request for an annual update advising that your project will continue without any changes that would affect ethical relations with human participants.

On behalf of the Chair of ICEHR, I wish to advise that the ethics clearance for this project has been extended to October 31, 2020. The Tri-Council Policy Statement on Ethical Conduct for Research Involving Humans (TCPS2) requires that you submit another annual update to ICEHR on your project prior to this date.

We wish you well with the continuation of your research. 